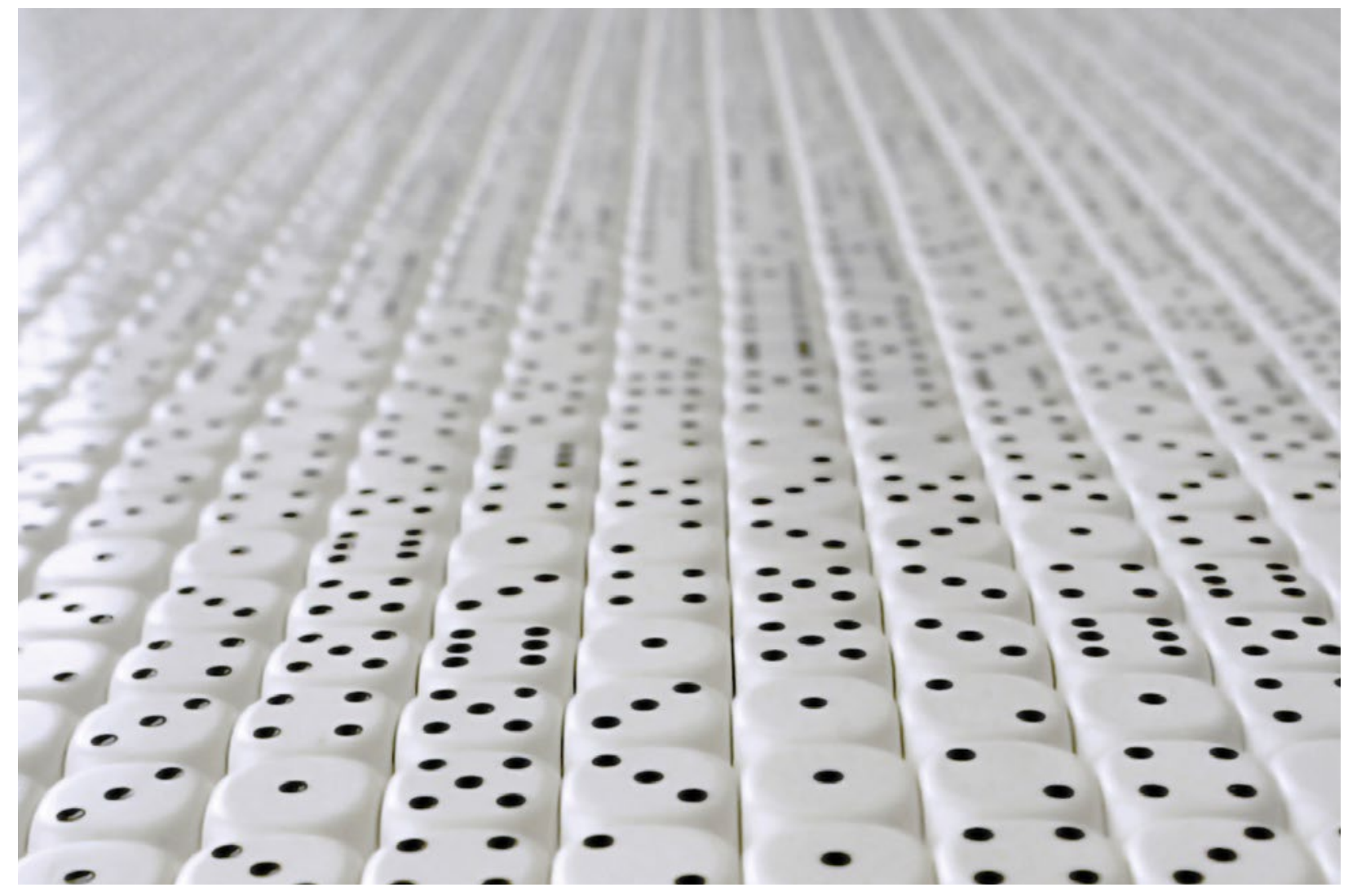

Trajectories of social and economic outcomes and problem gambling risk in Australia

\author{
M Fogarty, M Taylor and M Gray
}




\section{Series note}

The ANU Centre for Social Research \& Methods (CSRM) was established in 2015 to provide national leadership in the study of Australian society. CSRM has a strategic focus on:

- development of social research methods

- analysis of social issues and policy

- training in social science methods

- providing access to social scientific data.

CSRM publications are produced to enable widespread discussion and comment, and are available for free download from the CSRM website (http://csrm.cass.anu.edu.au/research/ publications).

CSRM is located within the Research School of Social Sciences in the College of Arts \& Social Sciences at the Australian National University (ANU). The centre is a joint initiative between the Social Research Centre and the ANU. Its expertise includes quantitative, qualitative and experimental research methodologies; public opinion and behaviour measurement; survey design; data collection and analysis; data archiving and management; and professional education in social research methods.

As with all CSRM publications, the views expressed in this Working Paper are those of the authors and do not reflect any official CSRM position.

\section{Professor Matthew Gray}

Director, ANU Centre for Social Research \& Methods

Research School of Social Sciences

College of Arts \& Social Sciences

The Australian National University

May 2018

Working Paper No. 9/2018

ISSN 2209-1858

ISBN 978-1-925715-00-2

An electronic publication downloaded from

http://csrm.cass.anu.edu.au/research/publications.

For a complete list of CSRM working papers, see http://csrm.cass.anu.edu.au/research/publications/ working-papers.

ANU Centre for Social Research \& Methods Research School of Social Sciences

The Australian National University 


\title{
Trajectories of social and economic outcomes and problem gambling risk in Australia
}

\author{
M Fogarty, M Taylor and M Gray
}

Marisa Fogarty is the Director of the Centre for Gambling Research, Centre for Social Research \& Methods, Research School of Social Sciences, College of Arts \& Social Sciences, Australian National University.

Matthew Taylor is a Senior Research Specialist at the Centre for Social Research \& Methods, Research School of Social Sciences, College of Arts \& Social Sciences, Australian National University.

Matthew Gray is a Professor of Social Policy and the Director of the Centre for Social Research \& Methods, Research School of Social Sciences, College of Arts \& Social Sciences, Australian National University.

\section{Abstract}

Researchers are increasingly recognising the importance of longitudinal data in providing valuable information on individuals to better understand gambling behaviour, trajectories, risks and consequences. However, relatively few longitudinal surveys have a significant focus on gambling. This paper makes use of a longitudinal data source that has, for the first time, included questions on gambling behaviour in Australia: the Household, Income and Labour Dynamics in Australia (HILDA) survey. The HILDA survey included gambling questions for the first time in 2015 (wave 15). Although the HILDA survey currently provides data on gambling at a single point in time, there are data on the individuals back to 2001, in most cases. This paper uses selected social, economic and health variables, and analyses their trajectories over time across the gambling risk categories measured in 2015. The paper explores economic variables (household income, employment, qualifications, financial hardship, risk and stress) and selected social variables (life satisfaction, psychological distress, alcohol intake and smoking) from multiple HILDA waves. The analysis clearly shows that problem gamblers experience significantly worse outcomes than those without gambling problems, and poor outcomes go back a number of years. In a number of cases, outcomes are becoming progressively poorer, which may suggest either increasingly risky gambling behaviour or the cumulative effects of a sustained period of problem gambling. Low- and moderaterisk gamblers have better economic, social and health outcomes than problem gamblers, but, in most cases, worse outcomes than those without gambling-related problems. Again, these differences go back a number of years. Exploring these particular variables in respect of problem gambling risk provides insights that may inform prevention and early intervention strategies to reduce gambling harm. 


\section{Acknowledgments}

This paper is a product of the core work of the ANU Centre for Gambling Research (CGR), Centre for Social Research \& Methods. CGR was established in 2002 as a joint partnership between the Australian Capital Territory Government and the Australian National University.

This paper uses unit record data from the Household, Income and Labour Dynamics in Australia (HILDA) survey. The HILDA project was initiated and is funded by the Australian

\section{Acronyms}

HILDA Household, Income and Labour Dynamics in Australia

PGSI Problem Gambling Severity Index

SCQ self-completion questionnaire
Government Department of Social Services (DSS) and is managed by the Melbourne Institute of Applied Economic and Social Research (Melbourne Institute). The findings and views reported in this paper, however, are those of the authors and should not be attributed to either DSS or the Melbourne Institute.

The authors are grateful to Dr Stephanie Merkouris and Dr Matthew Stevens for comments on an earlier version of this paper. 


\section{Contents}

Abstract _ iii

Acknowledgments _ iv

Acronyms

1 Introduction 1

2 The Household Income and Labour Dynamics in Australia (HILDA) survey ___ 3

2.1 Overview of the HILDA survey and measurement of gambling risk __ 3

2.2 Analytical sample _ 4

2.3 Outcome measures _ـ 4

3 Data analysis __ 7

3.1 Contemporaneous relationship between gambling risk and economic and social outcomes_ 7

3.2 Trajectories in economic and social outcomes according to gambling risk __ 9

3.3 Multivariate estimates of the relationship between gambling risk and economic and social wellbeing _ـ 17

3.4 Experience of 'negative' major life events __ 18

4 Conclusion 20

$\begin{array}{ll}\text { Appendix — } 21 & 21\end{array}$

Notes

$\begin{array}{ll}\text { References } & 26\end{array}$

\section{Tables and figures}

Table $1 \quad$ Level of problem gambling risk, 2015

Table 2 Outcome measures__ 5

Table $3 \quad$ Individual and household characteristics by level of problem gambling risk, $2015 \_8$

Figure 1 Level of problem gambling risk, by median gross annual (a) individual income and (b) equivalised household income, 2001-15_ 10

Figure 2 Proportion employed, by level of problem gambling risk, 2001-15 11

Figure 3 Proportion of individuals reporting three or more experiences of financial hardship, by level of problem gambling risk, 2001-15

Figure 4 Proportion of individuals reporting difficulty paying overdue (a) household bills and (b) personal bills, by level of problem gambling risk in 2006, 2010 and 2014

Figure 5 Proportion of individuals who paid-off own credit card balance by due date, by level of problem gambling risk in 2006, 2010 and 2014

Figure 6 Proportion of individuals who would take above-average financial risks with spare cash, by level of problem gambling risk, 2001-15 
Figure 7 Average life satisfaction score, by level of problem gambling risk, 2001-15

Figure 8 Proportion experiencing high and very high risk of psychological distress, by level of problem gambling risk, 2007, 2009, 2011, 2013 and 2015

Figure 9 Proportion who have more than four standard drinks, by level of problem gambling risk, 2002-15 16

Figure 10 Proportion who are current smokers, by level of problem gambling risk, 2001-15 16

Table 4 Relationship between gambling risk and economic, social and health outcomes, marginal effects, 2015 18

Table 5 Number of major life events experienced between 2002 and 2015 level of gambling risk 19

Table A.1 Estimated marginal effects for level of gambling problems for outcome measures, full results, 2015

Table A.2 Number of major life events experienced between wave 11 and 15 by level of gambling problems (balanced panel) 


\section{Introduction}

The Australian literature on the prevalence of gambling problems and the characteristics of those who gamble is extensive. Australian gambling research has predominantly been based on cross-sectional survey data, often from state/territory-based prevalence surveys that take a snapshot of gambling risk prevalence rates in a particular population at a point in time.

Researchers are increasingly recognising that longitudinal data that provide information on the gambling behaviour and the impacts of gambling on individuals are required to properly understand gambling behaviour, trajectories, risks and consequences. However, relatively few longitudinal surveys have a significant focus on gambling. Delfabbro et al. (2014) suggest that there have been very few 'rigorous and genuine longitudinal designs' in Australia. Notable exceptions are the Victorian Gambling Study (Billi et al. 2014, 2015), the Tasmanian Longitudinal Study (ACIL Allen Consulting et al. 2015) and a study of Australian adolescent to adult gambling (Delfabbro et al. 2014).

The largest scale Australian longitudinal study is the Victorian Gambling Study (2008-12). This study started with a cross-sectional sample of 15000 Victorians in the first wave of interviews. Of those interviewed in the first wave, 7148 agreed to participate in follow-up interviews, with 5003 participating in the second wave, 5620 in the third wave and 3701 in the fourth wave. The study found that, over 4 years, problem gamblers were likely to remain problem gamblers and that those groups that were defined as zero-risk (nongambler and nonproblem gambler) were also relatively stable. The study found that low-risk and moderate-risk gamblers were more likely to shift risk categories over the 4 years of the study (Billi et al. 2014). Although the Victorian Gambling Study is a landmark Australian study, producing unique and valuable data, high rates of interviewees did not participate in follow-up interviews, which means that there are concerns about the representativeness of the later waves of data.
The paucity of large-scale Australian longitudinal data means that there is a limited understanding of the trajectory of the economic, social and health outcomes experienced by those with different levels of gambling risk.

This report uses data from the Household, Income and Labour Dynamics in Australia (HILDA) survey, a large Australian longitudinal survey. The HILDA survey included gambling questions for the first time in 2015 (wave 15). This means that, while the HILDA survey currently provides data on gambling at a single point in time, there are data on the individuals back to 2001 in most cases and back to 2011 for a smaller group of participants who were recruited as a top-up sample.

This paper uses selected social, economic and health variables, and provides analysis of their trajectories over time (i.e. previous HILDA waves) across the gambling risk categories measured in 2015. Exploring particular social and economic variables in respect to problem gambling risk has the potential to provide insights that may inform prevention and early intervention strategies to reduce gambling harm. This paper explores economic variables (household income, employment, qualification, financial hardship, risk and stress) and selected social variables (life satisfaction, psychological distress, alcohol intake and smoking) from multiple HILDA waves in respect to problem gambling risk.

The main limitation of using the HILDA dataset is that we do not have information on gambling behaviour before 2015 (wave 15). However, it does provide valuable information of the retrospective trajectories of those identified as at-risk gamblers in 2015. The work of Billi et al. (2014) indicates that problem gambling behaviours are often longer term.

There has been some analysis of the HILDA gambling questions. Wooden and Wilkins (2017) analysed the data, specifically looking at participation, problem gambling and subjective 
wellbeing. In estimating problem gambling prevalence in the Australian population, $1.5 \%$ of men and $0.8 \%$ of women (around 200000 people) were found to experience severe negative consequences and a possible loss of control of their gambling, and therefore are classified as problem gamblers (Wooden \& Wilkins 2017). In addition, close to $8 \%$ of the population (1.4 million people) reported at least one harmful consequence as a result of their gambling. Further analysis of the HILDA data on gambling participation and expenditure, by Armstrong and Carroll (2017), found that gamblers in the lowest income quintile households spent a much greater proportion of their household income on gambling than did those in the highest income households. Armstrong and Carroll (2017) also found that gamblers who had problems (combined risk categories), representing $17 \%$ of regular gamblers, accounted for nearly half of all expenditure by regular gamblers. The gamblers who had problems also spent approximately one-third of their typical gambling expenditure on poker machines (Armstrong et al. 2017:46). 


\section{The Household Income and Labour Dynamics in Australia (HILDA) survey}

\subsection{Overview of the HILDA survey and measurement of gambling risk}

This section provides an overview of the gambling questions in the HILDA survey, and of the economic, social and health outcomes examined in this paper.

HILDA is a longitudinal household survey, which began in 2001. The survey collects a wide range of information, including income and labour market dynamics; educational participation; family circumstances; and social, health and economic wellbeing. The initial wave of data collected was from 7682 households and 19914 individuals. The 11th wave of the survey, in 2011, included an additional 2153 households comprising 5477 responding people (Summerfield et al. 2016). All household members aged 15 years and over are interviewed each year.

Questions about gambling were included in HILDA for the first time in 2015 (wave 15). ${ }^{1}$ Questions were asked about how much the respondent spent on different types of gambling in 'a typical month'. The types of gambling covered were instant scratch tickets ('scratchies'); bingo; Lotto or lottery games, such as Powerball or Oz Lotto; Keno; private betting (e.g. playing cards or mahjong with friends and family); poker; casino table games (e.g. blackjack, roulette); poker machines ('pokies') or slot machines; betting on horse or dog races (but not sweeps); and betting on sports.

Respondents were also administered the Problem Gambling Severity Index (PGSI) (Ferris \& Wynne 2001), a screening instrument designed to assess problem gambling risk. The PGSI asks about a range of negative consequences and behavioural symptoms over the previous 12 months:

- Have you bet more than you could really afford to lose?

- Have you needed to gamble with larger amounts of money to get the same feeling of excitement?

- When you gambled, did you go back another day to try to win back the money you lost?

- Have you borrowed money or sold anything to get money to gamble?

- Have you felt that you might have a problem with gambling?

- Has gambling caused you any health problems, including stress or anxiety?

- Have people criticised your betting or told you that you had a gambling problem, regardless of whether or not you thought it was true?

- Has your gambling caused any financial problems for you or your household?

- Have you felt guilty about the way you gamble or what happens when you gamble?

The response options are 'never', 'sometimes', 'most of the time' or 'almost always'. The PGSI is constructed by scoring each answer from 0 ('never') to 3 ('almost always') and summing over each item to form a score from 0 to 27 . Ferris and Wynne (2001) recommend using the scale to form five groups of gambling behaviour:

- nongambling - did not gamble in the preceding 12 months

- nonproblem gambling (PGSI score of 0 for those who gambled in the past 12 months)

- low level of problems, with few or no identified negative consequences (PGSI score between 1 and 2) 
- moderate level of problems leading to some negative consequences (PGSI score between 3 and 7 )

- problem gambling with negative consequences and a possible loss of control (PGSI score of 8 or higher).

In Ferris and Wynne's original construction, these items are administered to those who participated in at least one form of gambling in the previous 12 months. The administration of the instrument in HILDA differs in that all study members are asked these questions. Although those who did not gamble in the previous 12 months would be expected to respond 'never' to all items, in the HILDA data these respondents cannot be separated from those who did gamble in the previous 12 months but did not report any of these behaviours or issues related to their gambling. For this reason, this paper follows Wooden and Wilkins (2017) and presents results for a combined group of respondents, which includes those who did not gamble in the previous 12 months and those who may have gambled but did not report problems associated with their gambling behaviour. We refer to this group of respondents as those with "no problems'.

The questions on gambling are included in the self-completion questionnaire (SCQ) part of the survey. The SCQ is different to the rest of the survey in that the interviewers leave the SCQ with respondents to be picked up later or returned by mail. The SCQ contains more sensitive questions on parenting, work-life balance, relationship quality and attitudes, and social values that some respondents might not feel comfortable answering in a face-to-face interview.

\subsection{Analytical sample}

The sample used in the analysis are respondents who completed the PGSI in wave 15.

To maximise the sample size, the analysis includes respondents who were missing from previous waves because they did not participate that year or did not respond to the relevant HILDA questions. As a result, the sample size for wave 15 is larger than that for the previous waves. Of the 17606 respondents to wave 15, 15349 returned the SCQ. ${ }^{3}$

Information on the sample size for each gambling risk group is provided in Table 1. The estimated prevalence rates are broadly in line with the results of gambling prevalence studies (e.g. Davidson et al. 2015, Hare 2015). Although the number of respondents classified as being a problem gambler is relatively small (159 or $1.0 \%$ ), it is large enough to support a basic statistical analysis.

\subsection{Outcome measures}

An overview of the economic, social and health outcome measures and other variables analysed in this paper is provided in Table 2.

\section{Table 1 Level of problem gambling risk, 2015}

$\begin{array}{lrrr}\text { Level of problem gambling risk } & \text { Percentage } & \text { Sample size } & \text { Weighted frequency } \\ \text { No problems } & 92.4 & 13974 & 17044861 \\ \text { Low risk } & 4.0 & 603 & 744755 \\ \text { Moderate risk } & 2.5 & 375 & 465478 \\ \text { Problem gambling } & 1.0 & 159 & 197779\end{array}$

Note: Estimates are weighted using the self-completion questionnaire cross-section frequency weights.

Source: Household Income and Labour Dynamics in Australia (release 15) 


\section{Table 2 Outcome measures}

Variable Description

Income

Personal gross (before tax) annual income (\$ per year). Income is for the financial year before the interview. Missing values are imputed. Income has been converted to 2017 dollars using the Consumer Price Index.

Equivalised household income Total household financial year gross income adjusted to take into account different household sizes and demographic composition. This allows a measure of financial living standards that can be compared across households of different sizes and compositions. The new OECD equivalence scale is used, which takes a value of 1 for the first adult in a household, and adds 0.5 for each subsequent adult and 0.3 for each child. Income has been converted to 2017 dollars using the Consumer Price Index.

Employed (\%)

Those who worked in a job, business or farm in the 7 days before interview or who were on leave from a job.

Hardships related to a lack of money
Experiences of financial hardship are asked of respondents in HILDA who provide 'yes' or 'no' answers to the following statements:

- Could not pay electricity, gas or telephone bills on time

- Could not pay the mortgage or rent on time

- Pawned or sold something

- Went without meals

- Was unable to heat home

- Asked for financial help from friends or family

- Asked for help from welfare/community organisations.

The variable captures those who responded 'yes' to at least three of these questions.

Unpaid household bills ${ }^{\mathrm{a}}$

The household informant is asked, 'Does this household have any unpaid bills from this list that are now overdue?', where the list includes electricity, gas, water and sewerage, telephone (excluding mobile phones), council rates, rent or strata fees, home and contents insurance, child care, school fees, and pay TV or internet connections. This variable captures households where the household informant indicated that the household had outstanding bills.

Unpaid personal bills ${ }^{a}$

Each respondent is asked, 'Do you have any unpaid personal bills of this sort that are now overdue?' The respondent is given guidance as to what constitutes 'personal bills', such as mobile telephone, car registration and insurance, and gym membership. Respondents are specifically asked to not include personal loans, credit card bills or household bills (such as the rent or the electricity bill) because the household informant would have answered questions on household bills earlier in the HILDA interview. This variable captures people who indicated that they had outstanding personal bills other than their personal credit card.

Pay credit card on time
Respondents are asked, 'Did you pay off the entire balance owing on [the last] statement by the due date?' about credit cards that are solely in their name and not those held jointly with other household members. This variable captures people who had a personal credit card in their name and who indicated they could not pay off the entire balance owing by the due date. 


\section{Table 2 continued}

Variable Description

Attitudes to financial risk ${ }^{\mathrm{b}}$

Respondents are presented with various hypothetical scenarios that involve differing levels of risk and expected returns that are designed to measure their attitudes to financial risk. The variable used in this paper captures those who reported that they would take 'above-average financial risks, expecting to earn above-average returns' with their 'spare cash' that could be used for savings or investment, in addition to those who indicated they would 'take substantial financial risks expecting to earn substantial returns'. The counterfactual category includes those who reported that they would 'take average financial risks, expecting to earn average returns' and those who indicated that they were 'not willing to take any financial risks'. This measure excludes people who indicated that 'they never have spare cash'.

Life satisfaction

Respondents are asked, 'All things considered, how satisfied are you with your life?' and are asked to respond by giving a score between 0 (totally dissatisfied) and 10 (totally satisfied).

Psychological distress ${ }^{c}$

Measured using the Kessler-10 scale, which measures dimensions of anxiety and depression that an individual has experienced over the previous 4 weeks (Kessler et al. 2002). The measure used in this paper captures those with Kessler scores above 21 who are deemed to be experiencing 'high' or 'very high' levels of psychological distress. This level of distress has been found to be closely correlated with clinical diagnosis of mental illness.

Risky drinking

Respondents who drink alcohol are asked, 'On a day that you have an alcoholic drink, how many standard drinks do you usually have?' They are informed that a 'standard drink is a small glass of wine, a $285 \mathrm{ml}$ glass of regular beer, a nip of spirits, or a mixed drink'. This variable captures people who indicate that on a day that they drink they consume five or more standard drinks.

Smoking

Respondents are asked, 'Do you smoke cigarettes or any other tobacco products?' This variable captures those who indicated that they currently smoke.

HILDA = Household, Income and Labour Dynamics in Australia; OECD = Organisation for Economic Co-operation and Development

a The questions about unpaid bills and credit cards are asked as part of the rotating HILDA wealth module. They are only available for waves 2, 6, 10 and 14.

b Psychological distress is measured in waves 7, 9, 11, 13 and 15.

c Attitudes to risk are measured in all but waves 5, 7 and 9 . 


\section{Data analysis}

This section begins with a description of the bivariate associations between the economic, social and health outcome measures described in the previous section, and the PGSI gambling risk categories at the time that gambling risk was measured in HILDA. The longitudinal data in HILDA are then used to examine respondents' previous outcome measures in the waves leading up to the measurement of any gambling problems. This allows us to assess differences in the trajectories of these measures for groups that are observed to have different levels of gambling risk in 2015. The section that follows uses multivariate statistical techniques to assess the extent to which the differences in the outcome measures across the gambling risk groups observed in 2015 are due to differences in the demographic characteristics of the risk groups, independent of their level of gambling risk. Our data analysis concludes with a look at differences in the number of adverse life events experienced across the gambling risk groups between 2002 and 2015.

\subsection{Contemporaneous relationship between gambling risk and economic and social outcomes}

This section reports the relationship between problem gambling risk assessed in 2015 and a range of individual and household characteristics and outcomes (Table 3). ${ }^{4}$ No clear relationship is evident between gambling risk and individual income. Individuals who do not gamble have slightly lower median incomes than the low- and moderate-risk gamblers, and higher incomes than those who exhibit problem gambling behaviour. Individuals who report no gambling-related problems live in households with a higher median equivalised household income than those who are low-risk, moderate-risk or problem gamblers.
Despite the relatively small differences in income between low-risk, moderate-risk and problem gamblers, problem gamblers report much higher rates of financial hardship than do low- or moderate-risk gamblers. For example, $27.7 \%$ of problem gamblers reported experiencing three or more hardships related to a lack of money, while this was reported by $15.3 \%$ of moderaterisk gamblers and $11.0 \%$ of low-risk gamblers. Only $6.1 \%$ of those with no gambling-related problems reported experiencing three or more hardship events. A similar pattern is seen for overdue household and personal bills, and paying off credit cards on time. This pattern may reflect the effect of the financial losses experienced by problem gamblers on their financial position.

The lack of a clear relationship between gambling risk and income is consistent with the existing literature, which has found mixed results. For example, the 2012 New South Wales gambling prevalence report found no clear association between problem gambling and individual income, although the study found the prevalence of problem gambling was most frequent among those with an income of $\$ 30000-\$ 50000$ per year (Ogilvy Illumination 2012). However, the Northern Territory gambling prevalence survey found a U-shaped relationship, with higher rates of problem gambling among those with incomes less than $\$ 30000$ per year and those with incomes of more than $\$ 100000$ per year (Stevens et al. 2017). Using the HILDA data, Wooden and Wilkins (2017) found that higher income was associated with more gambling expenditure; however, greater net wealth was associated with lower levels of gambling expenditure. Their interpretation of the findings suggests that higher income facilitates more expenditure on gambling and that wealth is affected by, rather than causes, gambling problems. 
Table 3 Individual and household characteristics by level of problem gambling risk, 2015

\begin{tabular}{|c|c|c|c|c|c|}
\hline Measure & No problems & Low risk & Moderate risk & High risk & $P P$ value \\
\hline $\begin{array}{l}\text { Individual income - average } \\
\text { (\$ per year) }\end{array}$ & 53551 & 52412 & 52260 & 61545 & 0.001 \\
\hline $\begin{array}{l}\text { Individual income - median } \\
\text { (\$ per year) }\end{array}$ & 38950 & 41000 & 40319 & 35875 & - \\
\hline $\begin{array}{l}\text { Equivalised household } \\
\text { income - average } \\
\text { ( } \$ \text { per year) }\end{array}$ & 65779 & 58927 & 58547 & 69956 & 0.000 \\
\hline $\begin{array}{l}\text { Equivalised household } \\
\text { income - median ( } \$ \text { per year) }\end{array}$ & 55350 & 49883 & 46644 & 48488 & - \\
\hline Employed (\%) & 62.9 & 60.0 & 59.2 & 58.5 & 0.16 \\
\hline $\begin{array}{l}\text { Three or more experiences } \\
\text { of hardship (\%) }\end{array}$ & 6.1 & 11.0 & 15.3 & 27.7 & 0.000 \\
\hline Overdue household bills ${ }^{a}(\%)$ & 7.8 & 10.3 & 10.8 & 26.0 & 0.000 \\
\hline Overdue personal bills ${ }^{a}(\%)$ & 4.0 & 6.2 & 6.8 & 12.7 & 0.000 \\
\hline $\begin{array}{l}\text { Paid off credit card on time } \\
(\%)\end{array}$ & 69.9 & 57.9 & 46.2 & 34.2 & 0.000 \\
\hline Taking financial risks (\%) & 6.5 & 9.2 & 11.9 & 41.4 & 0.000 \\
\hline Life satisfaction & 8.0 & 7.8 & 7.6 & 7.0 & 0.000 \\
\hline Psychological distress (\%) & 16.4 & 23.5 & 27.0 & 53.8 & 0.000 \\
\hline $\begin{array}{l}\text { Five or more standard drinks } \\
\text { (\%) }\end{array}$ & 15.8 & 31.2 & 35.7 & 41.8 & 0.000 \\
\hline Smoking (\%) & 15.7 & 29.3 & 36.0 & 46.1 & 0.000 \\
\hline
\end{tabular}

$-=$ not applicable

a Variable collected in 2014.

Notes: A 1-way analysis of variance indicates that individual income, equivalised household income and life satisfaction are significantly different at a $1 \%$ level of significance. Fisher's exact test for the remaining variables indicates that these variables are statistically significant at a 1\% level of significance, with the exception of employment.

Source: Household Income and Labour Dynamics in Australia (release 15)

Problem gamblers have a slightly lower employment rate $(58.5 \%)$ than do those with no gambling-related problems (62.9\%), low-risk gamblers (60.0\%) and moderate-risk gamblers (59.2\%). However, great caution must be exercised in interpreting these differences in employment rates because differences in the age structure of the groups is not controlled for and employment rates vary considerably with age. ${ }^{5}$

Problem gamblers are much more likely to be willing to take high financial risk (41.4\%) than moderate $(11.9 \%)$ and low-risk gamblers $(9.2 \%)$. Just $6.5 \%$ of those with no gambling-related problems reported a high willingness to take financial risk.

Life satisfaction falls as level of gambling risk increases. ${ }^{6}$ Over half $(53.8 \%)$ of problem gamblers report high or very high psychological distress, compared with $16.4 \%$ of those with no gambling problems, $23.5 \%$ of low-risk gamblers and $27.0 \%$ of moderate-risk gamblers. The Kessler measure of psychological distress has often been used in gambling research (e.g. Blaszczynski et al. 2015) and the HILDA data are broadly consistent with the findings of this literature. ${ }^{7}$ 
The extent of heavy drinking also increases with level of gambling risk. The proportion of those with no gambling-related problems who have five or more standard drinks is $15.8 \%$, which increases to $41.8 \%$ among problem gamblers. Problem gamblers are also much more likely to be smokers than the other groups. For example, $46.1 \%$ of problem gamblers smoke compared with $15.7 \%$ of those with no problems.

Numerous studies have shown significant associations between gambling and behaviours that affect health, such as alcohol and smoking. Research suggests that gambling results in isolation and escape, and is often characterised by the consumption of goods that result in negative physical health, such as nicotine dependence and high alcohol consumption (Holdsworth et al. 2015).

\subsection{Trajectories in economic and social outcomes according to gambling risk}

An analysis of the economic, social and health outcomes from multiple HILDA waves in relation to problem gambling risk provides a picture over a fairly long period and allows us to examine the extent to which these outcomes vary according to the level of gambling risk.

Median income (individual and equivalised household) from 2001 to 2015 , according to problem gambling risk measured in 2015, is shown in Figure 1. Problem gamblers have a lower individual income than the other groups for the period 2013-15. Before 2013, the income of problem gamblers is relatively similar to that of the other groups. The individual incomes of those with no problems related to gambling, low- or moderate-risk gamblers are similar. The pattern of equivalised household incomes differs from that for individual income in that those reporting no gambling-related problems have substantially higher equivalised household incomes for all years, and problem gamblers have lower equivalised household incomes for only some years from 2011 to 2015.

Problem gamblers had a substantially lower employment rate from 2013 to 2015 than the other groups (Figure 2). The pattern is not so clear before 2013.

Figure 3 shows the proportion of respondents who experienced three or more finance-related hardships over the previous 12 months for the period 2002 to 2015, according to gambling risk measured in 2015. It is clear that those who report problem gambling behaviours are more likely to experience three or more financial hardships than those who report no gambling related problems; this is true of every year from 2002 to 2015 , except for 2003 (Figure 3). Low- and moderaterisk gamblers are also more likely to report having experienced three or more financial hardships, but this rate is lower than for problem gamblers. This pattern is found for most years from 2002 to 2015.

While some of those who were problem gamblers in 2015 will be long-term problem gamblers, this is unlikely to be the case for all of them. Other longitudinal studies have demonstrated transition probabilities, particularly a high probability of transitioning from moderate to high-risk categories (Billi et al. 2014). Although this does not present evidence of a causal relationship between financial hardship and problem gambling, it does suggest that there is a very distinct difference between people who do not experience problems with gambling and the level of financial hardship they face in comparison to high-risk problem gamblers over a 13-year period. Moreover, the relative rate of risk appears to increase in the waves approaching that where individuals report problem gambling behaviours. In 2015, the proportion of problem gamblers reporting three or more experiences of hardship is $24 \%$ - nearly 5 times that of those who did not report any problems. ${ }^{8}$

Further to understanding levels of financial hardship, difficulty paying bills is an alternative measure of adverse financial circumstances. Since the questions about unpaid bills and credit cards are asked as part of the rotating HILDA wealth module, they are only available for waves 6,10 and 14 .

Figure 4 presents a range of measures of household and individual liquidity constraints. The data suggest that high-risk problem gamblers report overdue household bills at significantly 
Figure 1 Level of problem gambling risk, by median gross annual (a) individual income and (b) equivalised household income, 2001-15

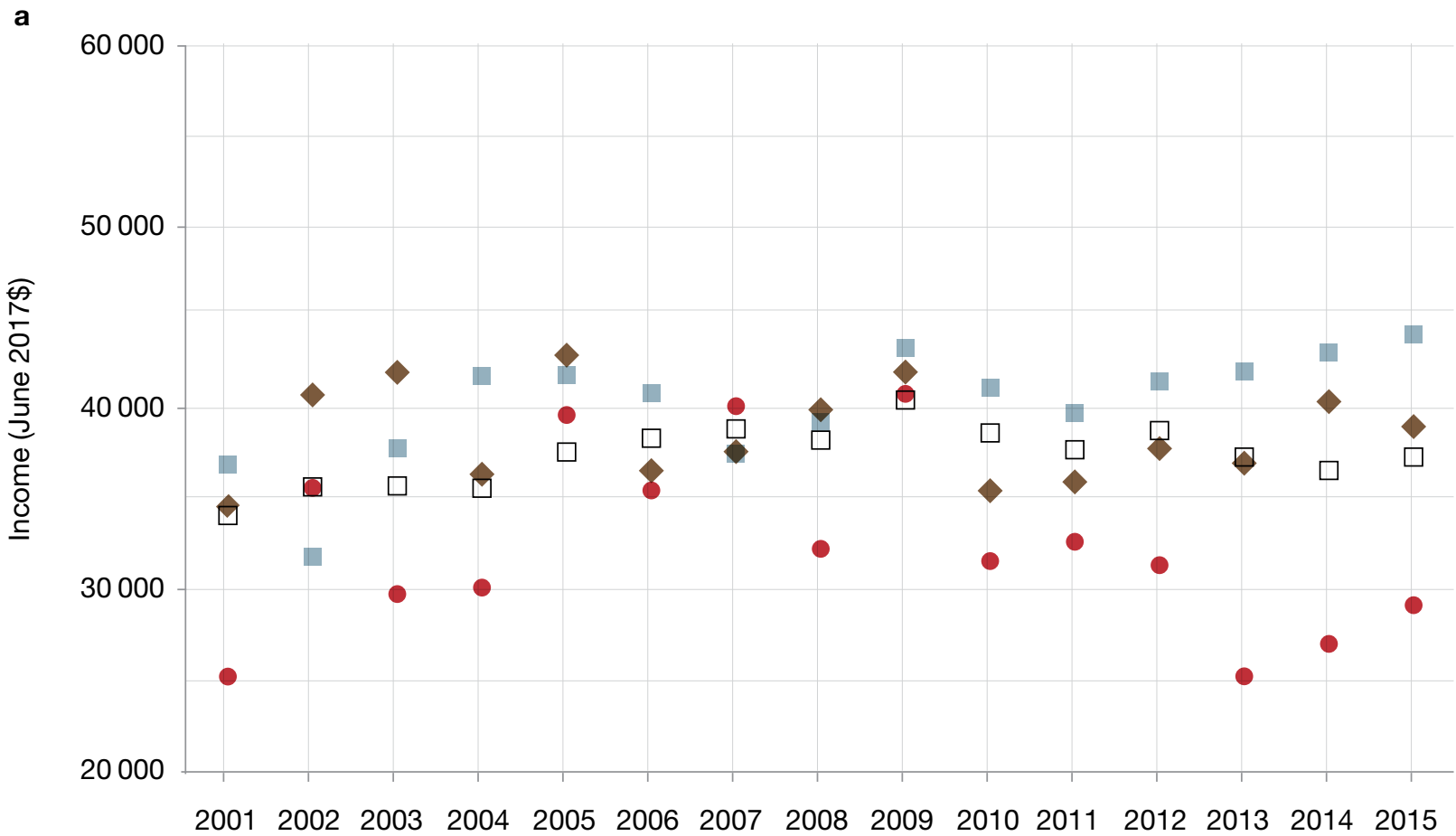

b

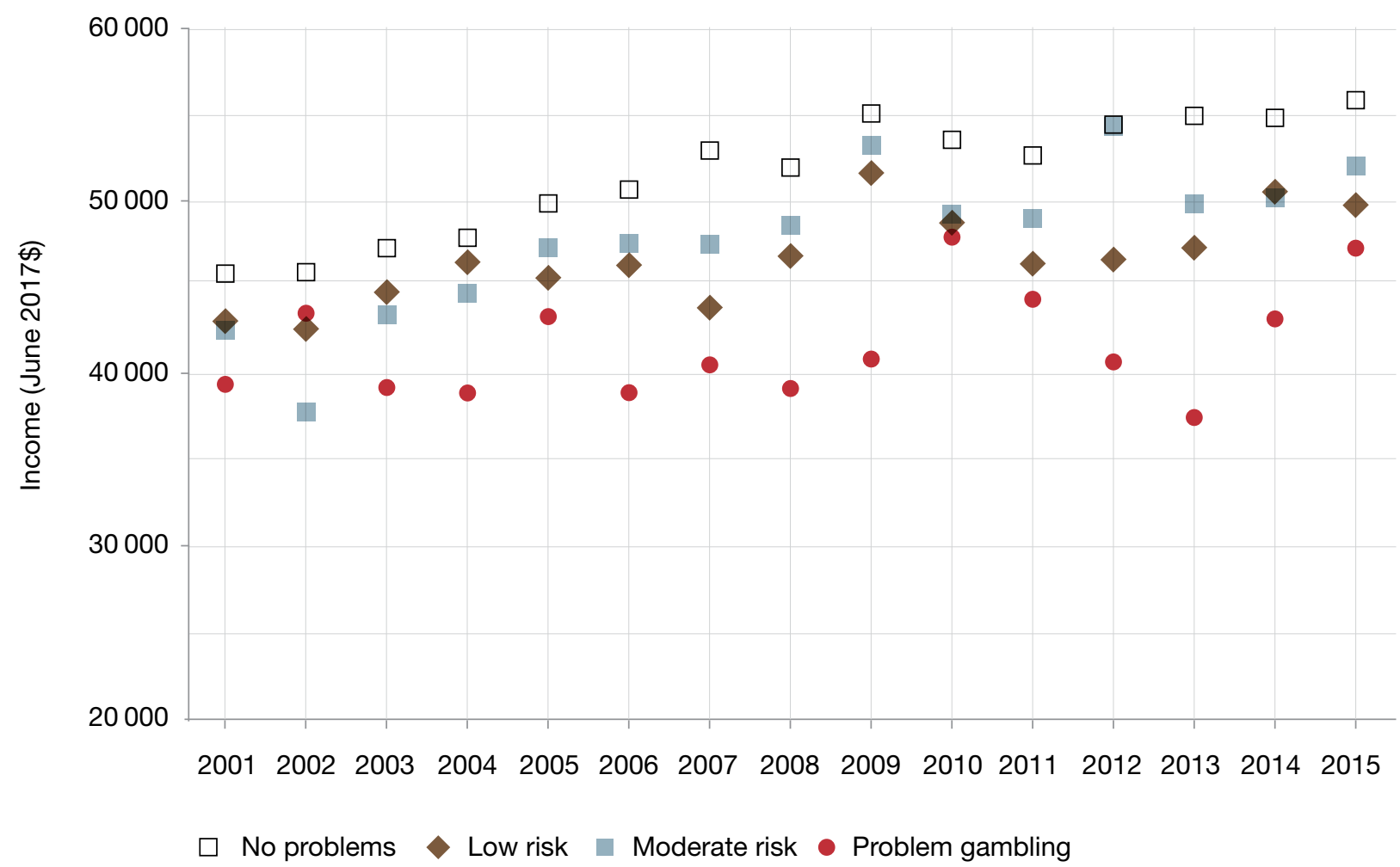

Notes:

1. Gambling risk was measured in 2015.

2. Estimates are weighted using the self-completion questionnaire cross-section frequency weights.

Source: Household Income and Labour Dynamics in Australia (release 15) 
Figure 2 Proportion employed, by level of problem gambling risk, 2001-15

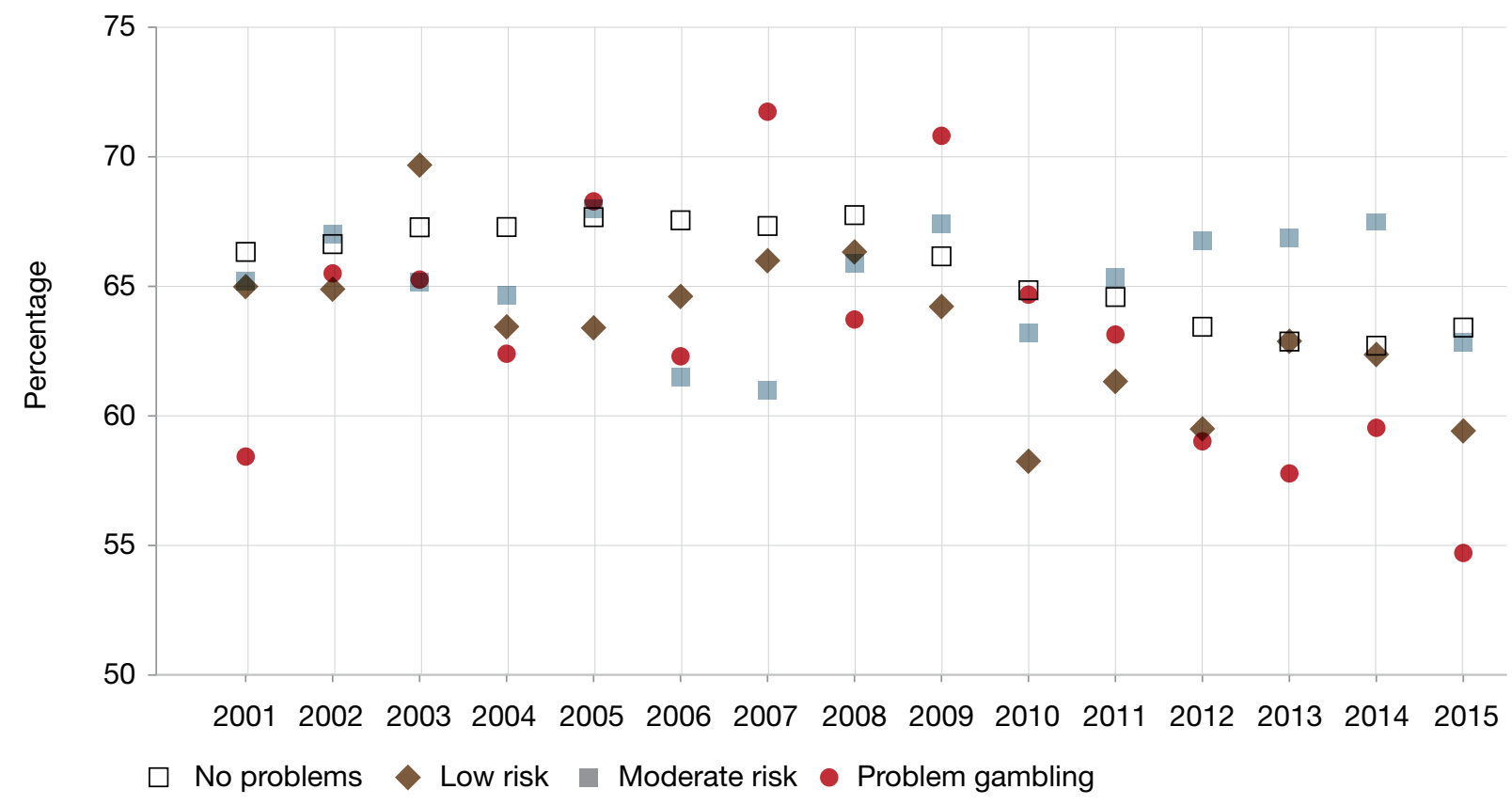

Notes:

1. Gambling risk was measured in 2015.

2. Estimates are weighted using the self-completion questionnaire cross-section frequency weights.

Source: Household Income and Labour Dynamics in Australia (release 15)

Figure 3 Proportion of individuals reporting three or more experiences of financial hardship, by level of problem gambling risk, 2001-15

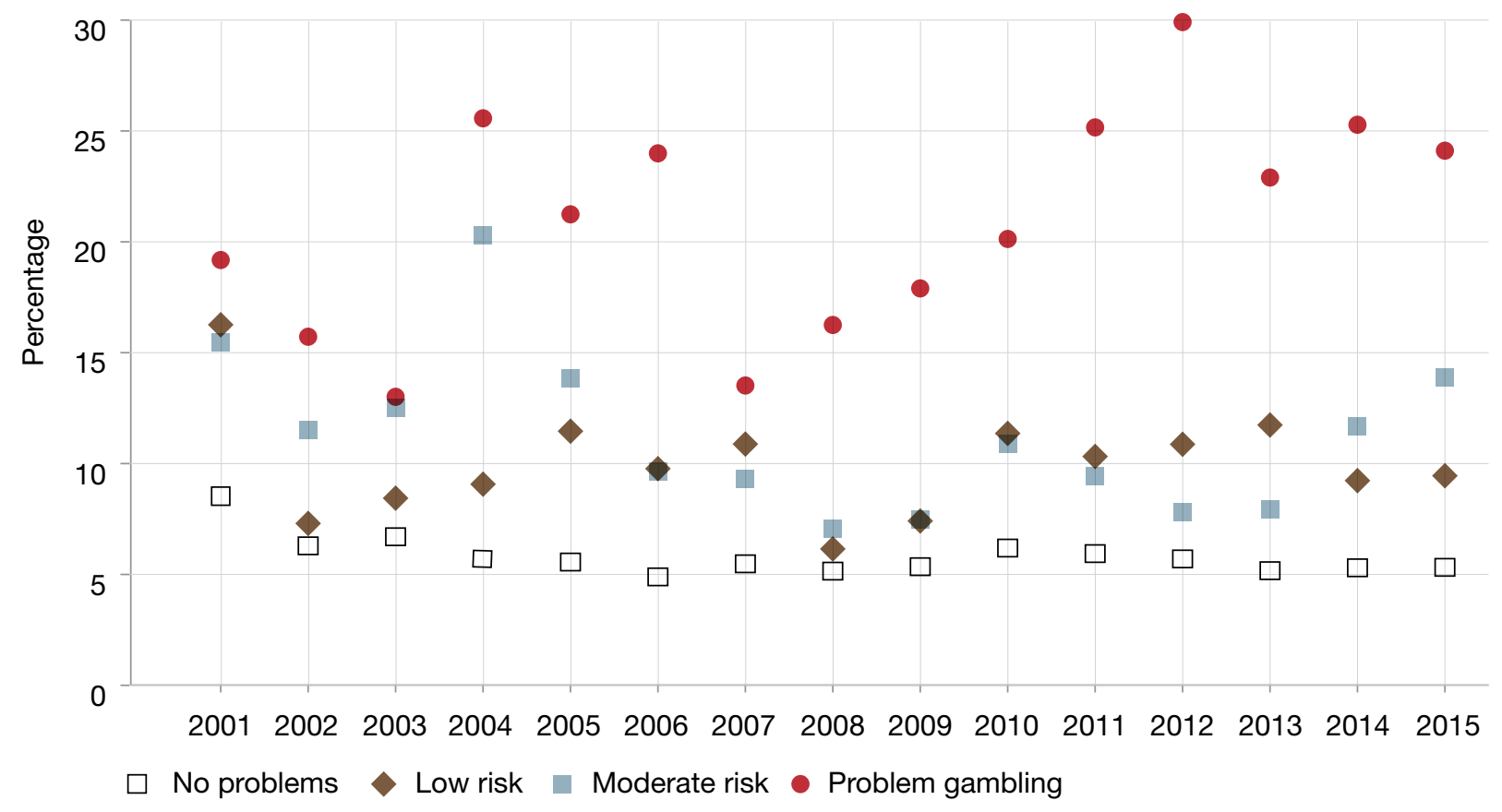

Notes:

1. Gambling risk was measured in 2015.

2. Estimates are weighted using the self-completion questionnaire cross-section frequency weights.

Source: Household, Income and Labour Dynamics in Australia (release 15) 
Figure 4 Proportion of individuals reporting difficulty paying overdue (a) household bills and (b) personal bills, by level of problem gambling risk in 2006, 2010 and 2014
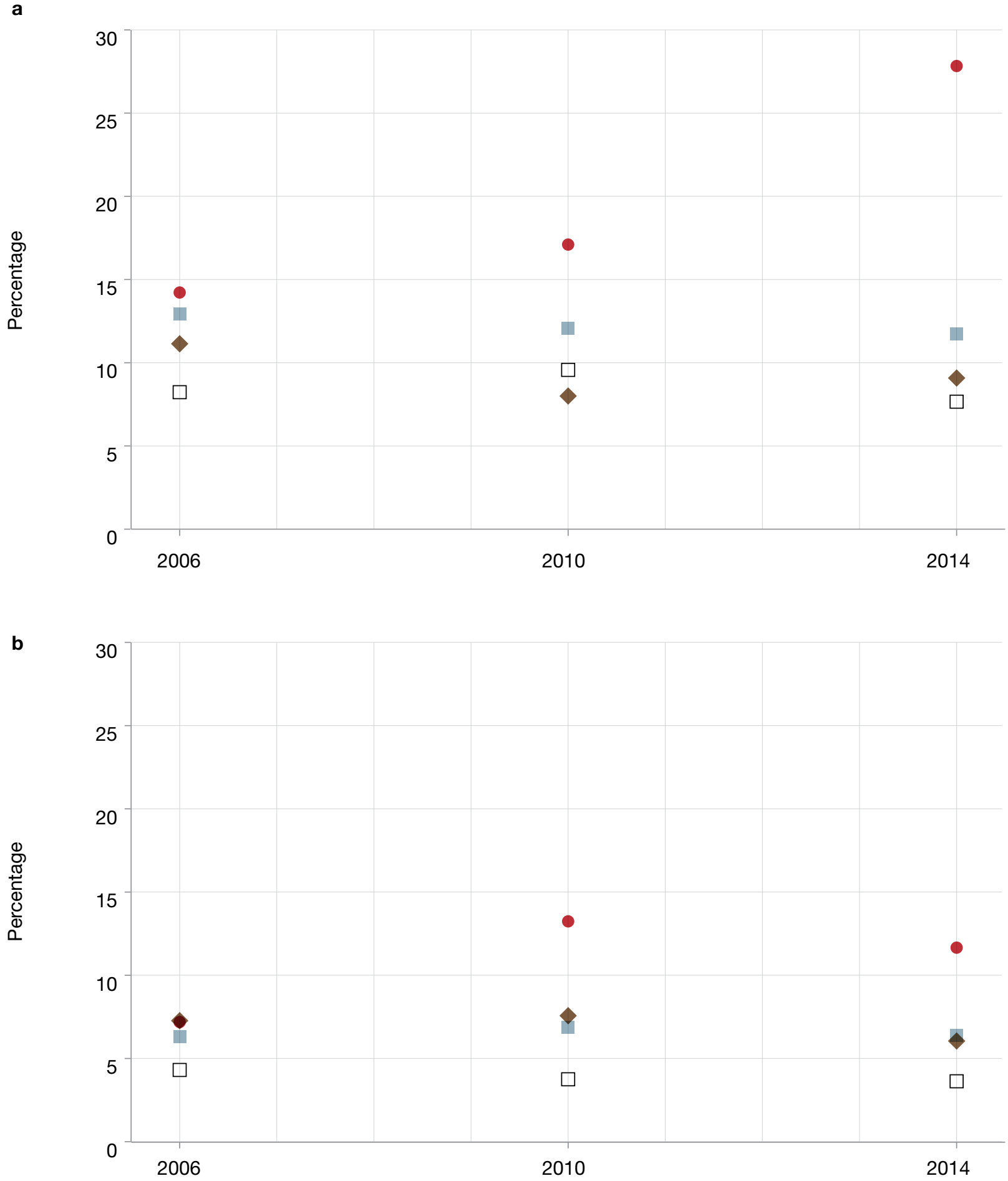

$\square$ No problems $\diamond$ Low risk $\square$ Moderate risk $\bullet$ Problem gambling

Notes:

1. Gambling risk was measured in 2015 .

2. Estimates are weighted using the self-completion questionnaire cross-section frequency weights.

Source: Household, Income and Labour Dynamics in Australia (release 15) 
higher rates than all other groups (Figure 4a). High-risk problem gamblers report overdue household bills at more than 3 times the rate of no-problem respondents and at more than 2 times the rate of moderate-risk gamblers.

The data also indicate that high-risk problem gamblers experience significantly higher rates of overdue personal bills than those who do not report problems (Figure 4b). Interestingly, highrisk problem gamblers report very high levels of difficulty paying overdue personal bills 5 years out from wave 15 that categorises them as high-risk problem gamblers, which is consistent with their reported experiences of financial hardship in Figure 3.

The data in Figure 5 suggest that those who report problem gambling at wave 15 are consistently less able to pay off their credit card balances in the preceding 13-year period than are those who report no gambling problems. At wave 15 , the proportion of problem gamblers who could pay their balance owing was half that of those who reported no problems.
The proportion of people reporting taking aboveaverage financial risks (expecting to earn aboveaverage returns) with their spare cash (that could be used for savings or investment) increases with gambling risk (Figure 6). Between 5\% and 10\% of those who reported no gambling problems in 2015 reported taking above-average financial risks. Low- and moderate-risk gamblers are more likely to report taking above-average financial risks than those reporting no gambling-related problems. However, only a minority of these groups report that they would take above-average financial risks (10-15\%). A much higher proportion of high-risk gamblers report that they would take above-average financial risks with spare cash, and this increased between 2011 and 2015 from $27 \%$ to $43 \%$. Although we cannot say for certain that the onset of high-risk gambling for some of these respondents occurred before 2011, it seems reasonable to speculate that high-risk gamblers in 2015 may have exhibited lower levels of risk aversion before the onset of problem gambling.

Figure 5 Proportion of individuals who paid-off own credit card balance by due date, by level of problem gambling risk in 2006, 2010 and 2014

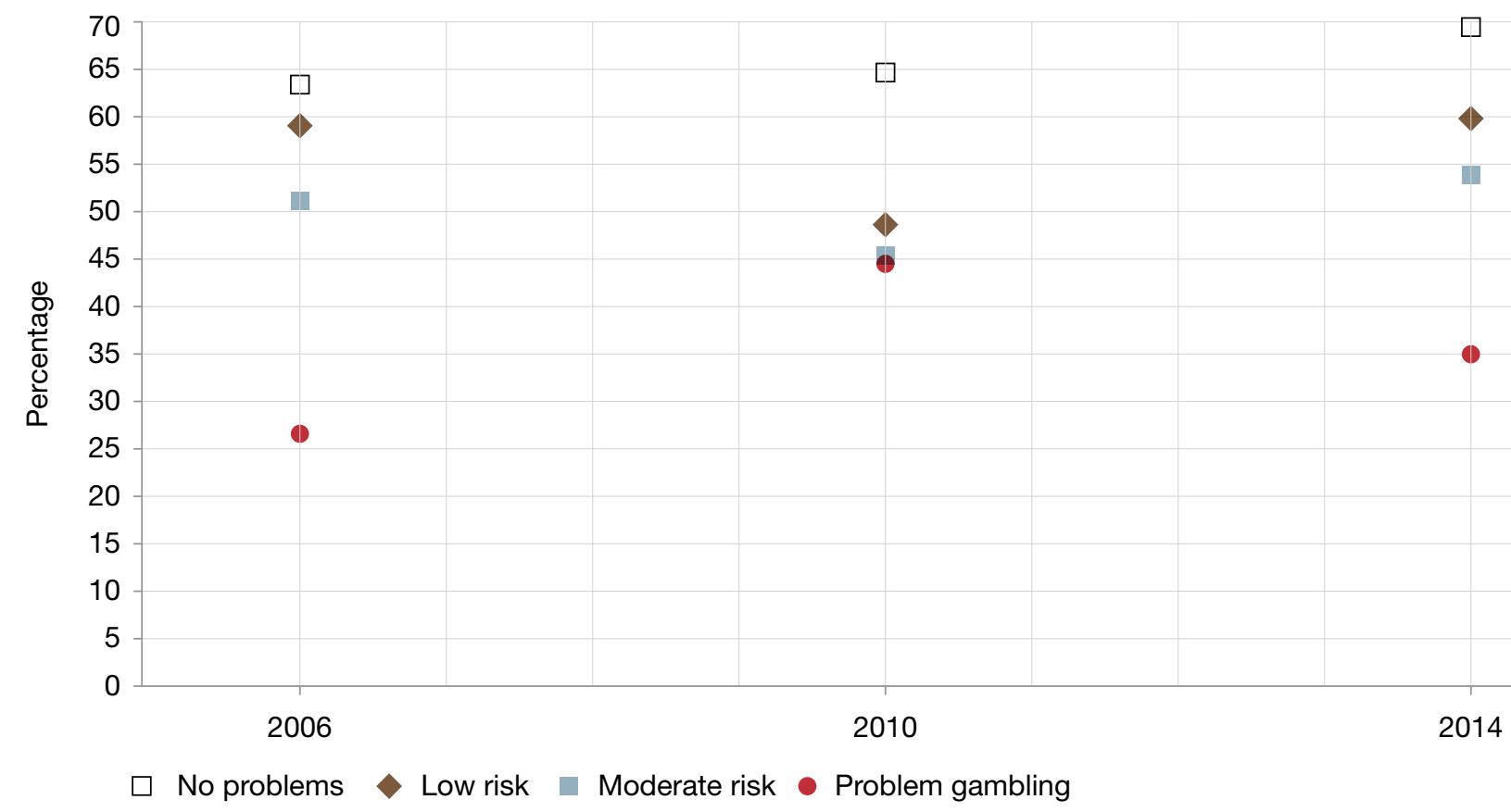

Notes:

1. Gambling risk was measured in 2015.

2. Estimates are weighted using the self-completion questionnaire cross-section frequency weights.

Source: Household, Income and Labour Dynamics in Australia (release 15) 
Figure 6 Proportion of individuals who would take above-average financial risks with spare cash, by level of problem gambling risk, 2001-15

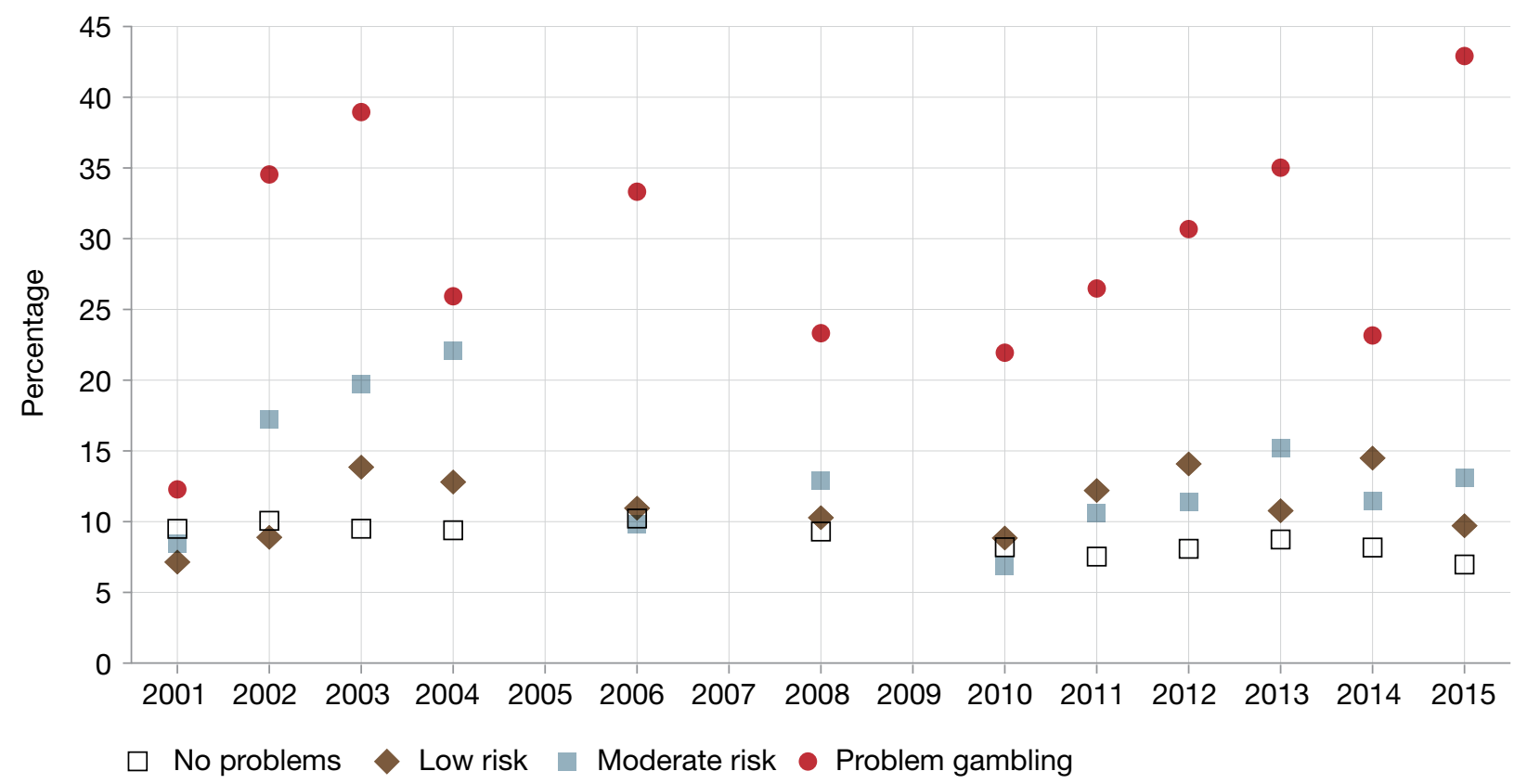

Notes:

1. Gambling risk was measured in 2015.

2. Estimates are weighted using the self-completion questionnaire cross-section frequency weights.

3. Attitudes to financial risk are measured in all but waves 5,7 and 9 .

Source: Household Income and Labour Dynamics in Australia (release 15)

Figure 7 Average life satisfaction score, by level of problem gambling risk, 2001-15

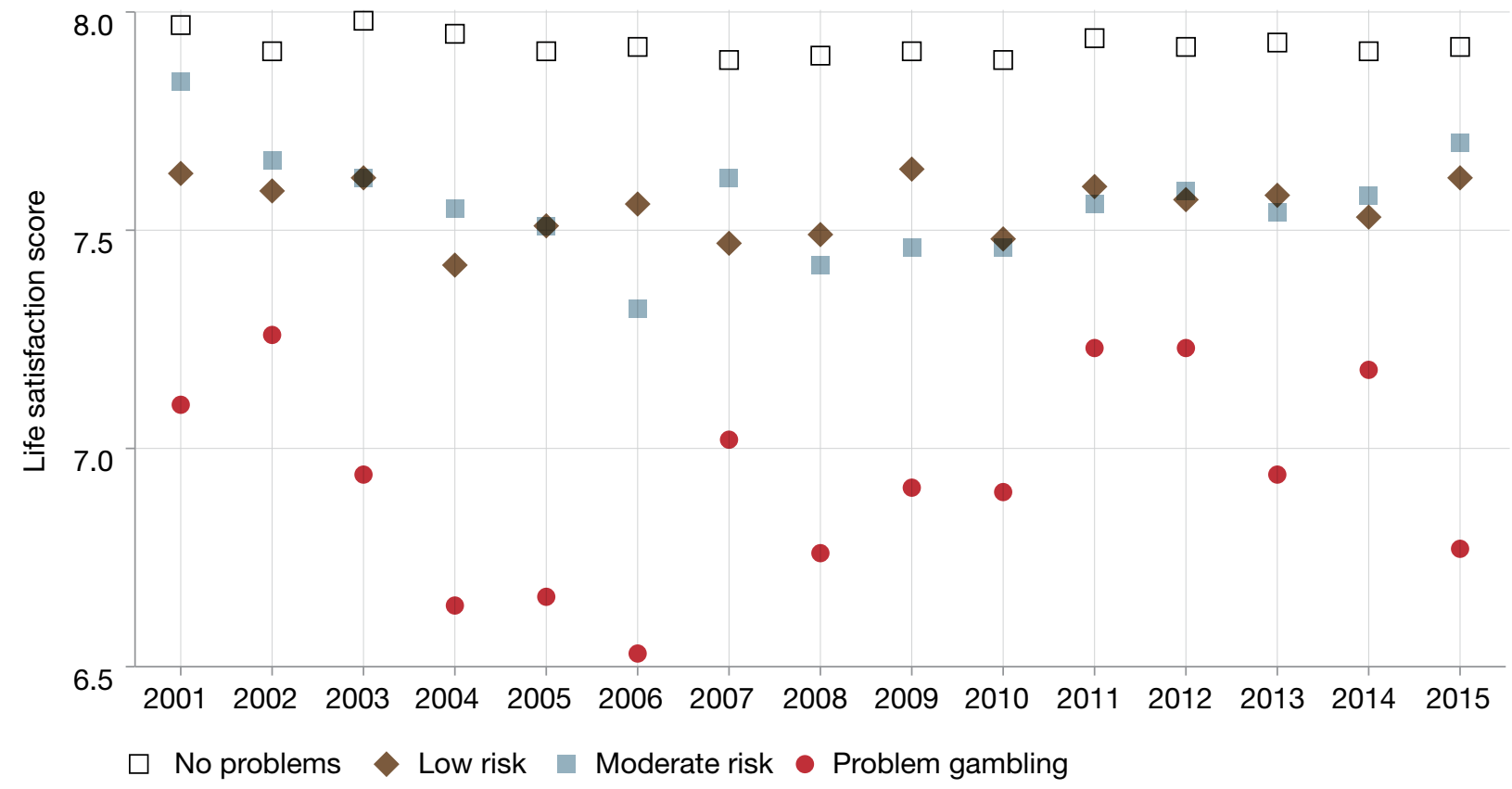

Notes:

1. Gambling risk was measured in 2015.

2. Estimates are weighted using the self-completion questionnaire cross-section frequency weights.

Source: Household Income and Labour Dynamics in Australia (release 15) 
High-risk problem gamblers experience significantly lower levels of reported life satisfaction (Figure 7). What is unique about this analysis is that high-risk problem gamblers report lower life satisfaction consistently over 13 years. No problem gambling respondents report very stable and consistent levels of life satisfaction over time. Very little difference is seen between the low- and moderate-risk groups, although they consistently report a lower level of life satisfaction than no-problem respondents.

High-risk problem gamblers were 2-3.5 times more likely to experience high or very high levels of psychological distress than any other groups in 2015 (Figure 8). What is clear from the analysis is that these high and very high levels of psychological distress are experienced consistently, and at significantly higher levels, over the five data collection points (9 years).

Those who reported no gambling-related problems were significantly less likely than lowand moderate-risk gamblers to experience high or very high levels of psychological distress.
Results for low- and moderate-risk gambling groups were not dissimilar from each other, although they experienced greater levels of psychological distress than no-problem respondents.

No-problem respondents report consuming more than four alcoholic drinks about half as often as the problem and the low- or moderate-risk groups (Figure 9). There are relatively small differences between low-risk, moderate-risk and problem gamblers, and no clear pattern over time.

A significantly higher proportion of high-risk problem gamblers smoked compared with the other groups between 2001 and 2015 (Figure 10). No-problem respondents have a very consistent pattern of low levels of smoking compared with the other groups. Interestingly, the data show a downward trend in rates of smoking by high-risk problem gamblers, which may reflect changes in regulation and taxation over the past 5 years leading to increases in people quitting.

Figure 8 Proportion experiencing high and very high risk of psychological distress, by level of problem gambling risk, 2007, 2009, 2011, 2013 and 2015

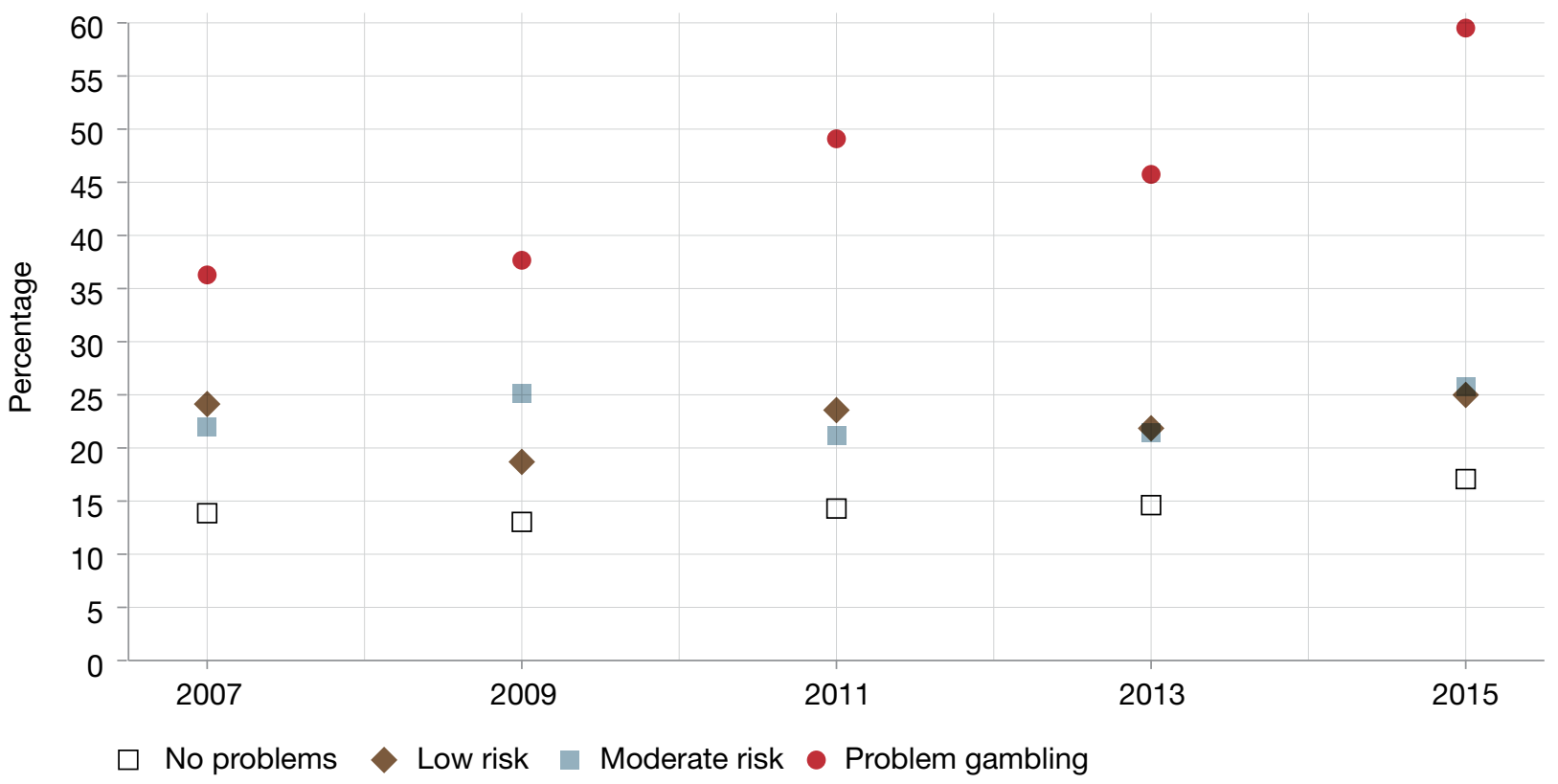

Notes:

1. Gambling risk was measured in 2015

2. The Kessler-10 scale is only administered in waves 7, 9, 11, 13 and 15.

3. Estimates are weighted using the self-completion questionnaire cross-section frequency weights.

Source: Household Income and Labour Dynamics in Australia (release 15) 
Figure 9 Proportion who have more than four standard drinks, by level of problem gambling risk, 2002-15

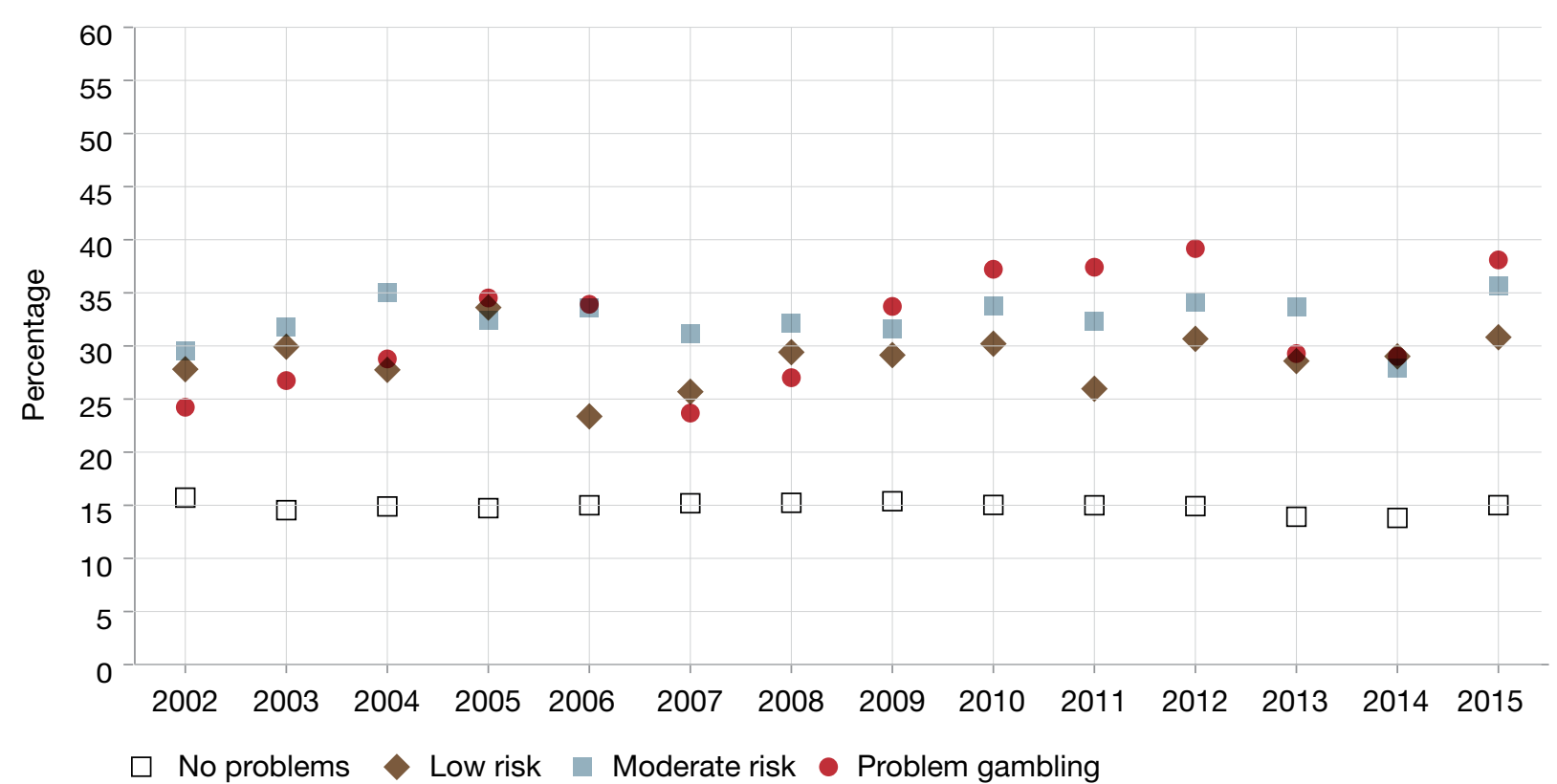

Notes:

1. Gambling risk was measured in 2015.

2. Estimates are weighted using the self-completion questionnaire cross-section frequency weights.

Source: Household Income and Labour Dynamics in Australia (release 15)

Figure 10 Proportion who are current smokers, by level of problem gambling risk, 2001-15

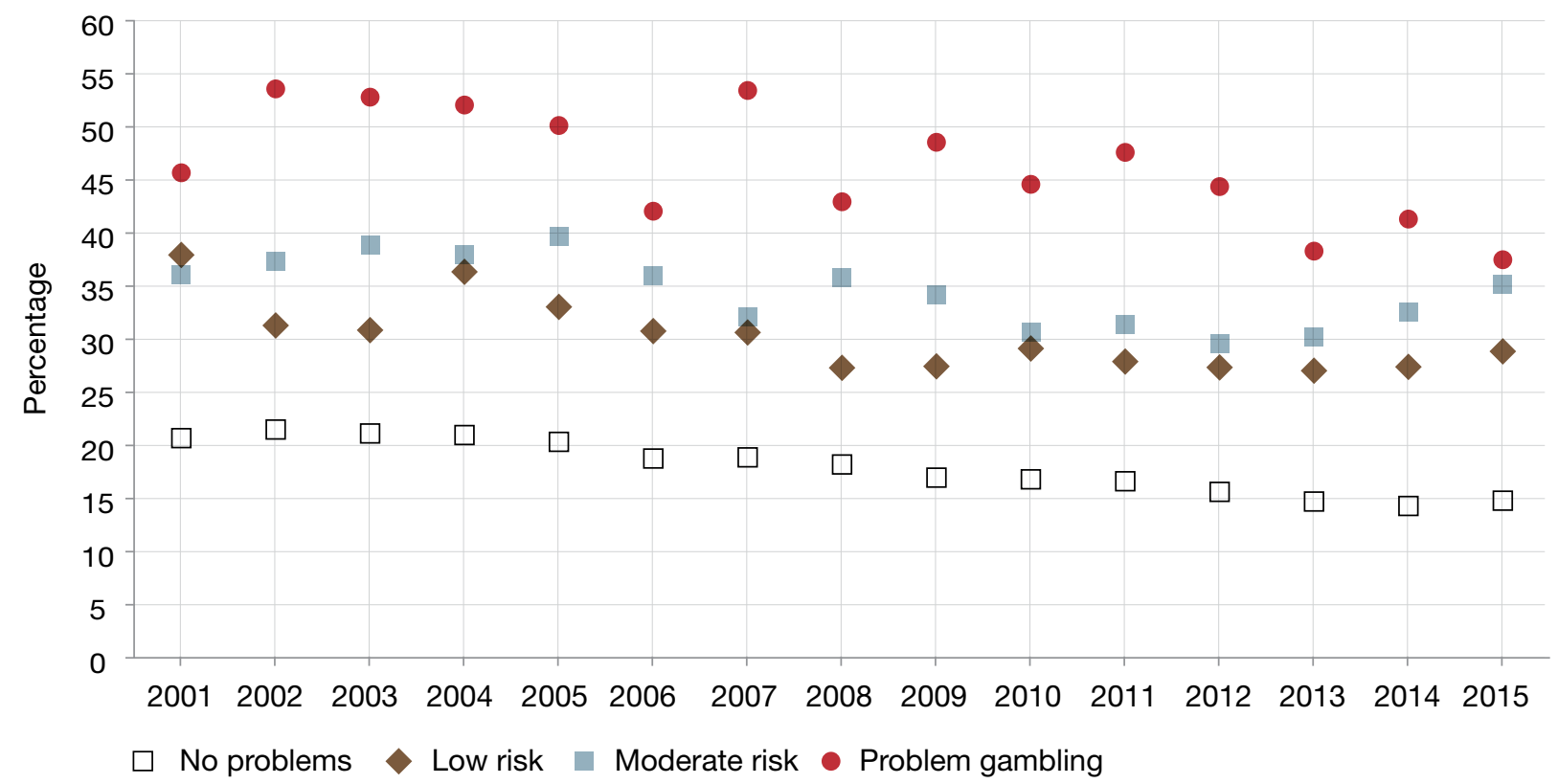

Notes:

1. Gambling risk was measured in 2015.

2. Estimates are weighted using the self-completion questionnaire cross-section frequency weights.

Source: Household Income and Labour Dynamics in Australia (release 15) 


\subsection{Multivariate estimates of the relationship between gambling risk and economic and social wellbeing}

The results presented above suggest that high-risk problem gamblers have, on average, more adverse outcomes across a range of measures than do those who do not gamble or gamble but do not experience any problems as a consequence (i.e. low- or moderate-risk gamblers). Low- and moderate-risk gamblers also experience worse outcomes than those without gambling problems, but generally better outcomes than problem gamblers. However, the analysis has not taken into account differences in demographic, human capital and other characteristics between the different groups, which may be related to differences in outcomes independent of gambling risk. For example, problem gamblers have, on average, a lower level of educational attainment than those with low- and moderate-risk gambling, a factor which is associated with worse economic, social and health outcomes. Failure to consider these factors may lead to misleading estimates of the effect of the level of gambling risk on outcomes.

This section presents the results of a regression analysis of the relationship between the level of gambling risk and economic, social and health outcomes. This enables us to estimate the relationship between gambling risk level and the various outcome measures, holding constant observable characteristics. The control variables included in the regression are gender, educational attainment, relationship status, age, Indigenous status, and state or territory of residence. With the exception of overdue household bills, overdue personal bills and ability to pay off one's own credit card, where the control variables are those relevant to wave 14 , for all other measures the control variables are those relevant to 2015 .

For continuous variables (individual income, equivalised household income and life satisfaction) the models are estimated using ordinary least squares. For the income variables, the dependent variable is the natural logarithm of income; Table 4 shows the percentage impacts on income. For the binary choice variables (i.e. outcomes that take the value of 0 or 1 ), a probit model is used. Because the probit model coefficient can be difficult to interpret, the effect of the explanatory variables on the outcome variable are reported using marginal effects, which show the effect of the change in the characteristics on the outcome variable, holding constant the value of the other explanatory variables in the model.

The effects of the various levels of gambling risk on the outcome variables, holding constant the effect of the other explanatory variables, are shown in the final three columns of Table 4 . The effects of gambling risk are reported relative to having no gambling-related problems. For most variables, increasing levels of gambling risk are estimated to have a negative impact on the outcome measure and, for most of the outcomes, problem gambling has a substantially greater negative impact on outcomes than does moderate-risk gambling. Most of the estimated marginal effects are statistically significant at a $5 \%$ level of significance and many are statistically significant at a $0.1 \%$ level.

As an example of the interpretation of the estimates, low-risk gambling is estimated to increase the likelihood of experiencing high or very high psychological distress by 6.1 percentage points compared with those with no gambling problems. Moderate-risk gambling is estimated to increase the risk by 9.3 percentage points and problem gambling by 31.1 percentage points (Table 4). The univariate difference (i.e. cross-tabulation) in the proportion of problem gamblers and those who reported no problems, in reported psychological distress, was 37.4 percentage points. This is only slightly higher than the marginal effect of 31.3 presented in Table 4. This indicates that controlling for those characteristics listed above reduces the gap in the probability of experiencing psychological distress by a modest amount. Therefore, the apparent effect of problem gambling cannot be explained by the observable characteristics included in the model.

The average percentage differences in personal income across the gambling risk groups changes considerably after controlling for demographic characteristics, suggesting that those with some level of gambling problem have higher incomes than those without problems. 


\section{Table 4 Relationship between gambling risk and economic, social and health outcomes, marginal effects, 2015}

\begin{tabular}{|c|c|c|c|c|c|c|}
\hline \multirow[b]{3}{*}{ Outcome } & \multicolumn{6}{|c|}{ Gambling risk level } \\
\hline & \multicolumn{3}{|c|}{ Unconditional differences } & \multicolumn{3}{|c|}{ Conditional differences } \\
\hline & Low risk & $\begin{array}{l}\text { Moderate } \\
\text { risk }\end{array}$ & $\begin{array}{l}\text { Problem } \\
\text { gambling }\end{array}$ & Low risk & $\begin{array}{l}\text { Moderate } \\
\text { risk }\end{array}$ & $\begin{array}{l}\text { Problem } \\
\text { gambling }\end{array}$ \\
\hline Individual income (\%) & -2.1 & -2.4 & 14.9 & $30.3^{\star \star \star}$ & $23.9^{\star}$ & $48.0^{*}$ \\
\hline $\begin{array}{l}\text { Equivalised household income } \\
\text { (\%) }\end{array}$ & -10.4 & -11.0 & 6.4 & -4.4 & $-11.6^{\star}$ & -1.5 \\
\hline Employment (pp) & -2.9 & -3.7 & -4.4 & 0.2 & 0 & -4.1 \\
\hline $\begin{array}{l}\text { Three or more experiences of } \\
\text { hardships (pp) }\end{array}$ & 4.9 & 9.2 & 21.6 & $3.7^{\star \star}$ & $7.2^{\star \star \star}$ & $14.7^{\star \star \star}$ \\
\hline Overdue household bills (pp) & 2.5 & 3.0 & 18.2 & 2.0 & 0.018 & $11.2^{* \star *}$ \\
\hline Overdue personal bills (pp) & 2.2 & 2.8 & 8.7 & 1.9 & 0.025 & $5.9^{\star \star}$ \\
\hline Paid off credit card on time (pp) & -12.0 & -23.7 & -35.7 & $-10.7^{\star \star *}$ & $-20.4^{\star \star \star}$ & $-27.6^{\star * *}$ \\
\hline Taking financial risks (pp) & 2.7 & 5.4 & 34.9 & $3.6^{*}$ & $6.7^{\star \star \star}$ & $38.1^{\star \star \star}$ \\
\hline Life satisfaction & -0.2 & -0.4 & -1.0 & $-0.167^{\star \star}$ & $-0.322^{\star \star \star}$ & $-0.877^{\star \star \star}$ \\
\hline Psychological distress (pp) & 7.1 & 10.6 & 37.4 & $6.0^{\star \star \star}$ & $9.3^{\star \star \star}$ & $31.1^{\star \star \star}$ \\
\hline $\begin{array}{l}\text { Five or more standard drinks } \\
\text { (pp) }\end{array}$ & 15.4 & 19.9 & 26.0 & $14.8^{\star \star \star}$ & $20.3^{\star \star \star}$ & $21.5^{\star \star \star}$ \\
\hline Smoking (pp) & 13.6 & 20.3 & 30.4 & $10.9^{\star \star \star}$ & $16.4^{\star \star \star}$ & $20.6^{\star \star \star}$ \\
\hline
\end{tabular}

${ }^{*}=P<0.05 ;{ }^{* \star}=P<0.01 ;{ }^{* \star \star}=P<0.001 ; \mathrm{pp}=$ percentage point

Notes:

1. Full results are presented in Table A.1 in the appendix.

2. Since the income regressions are estimated in terms of the natural log of income, the regression results are presented as percentage changes.

3. The unconditional results for the income variables are the averages observed in Table 3, presented as the average percentage change in income relative to the no problems group.

4. All other results are presented in levels such that all remaining results refer to percentage point changes, with the exception of life satisfaction.

Source: Household Income and Labour Dynamics in Australia (release 15)

This might reflect that having some discretionary income is necessary for higher levels of gambling expenditure. The results for household income and gambling problems are more in line with the unconditional results in Table 3. However, after controlling for individual characteristics, problem gamblers appear to have lower household incomes than those who do not experience gambling problems. It appears that the relationship between income, at the individual and household level, is complex and one that warrants further exploration.

\subsection{Experience of 'negative' major life events}

Each wave of the HILDA survey contains a question that asks about major life events that the respondent experienced during the previous 12 months. These include what might be seen as both negative and positive events. By cumulating individuals' experiences of 'negative' major life events over a 15-year period, we can understand more about differences in the lives of people over an extended period of time. Although most of the life events included in the analysis would generally be regarded as negative, an exception 


\section{Table 5 Number of major life events experienced between 2002 and 2015 level of gambling risk}

\begin{tabular}{|c|c|c|c|c|c|}
\hline \multirow[b]{2}{*}{ Life event } & \multicolumn{5}{|c|}{ Gambling risk level } \\
\hline & $\begin{array}{l}\text { No } \\
\text { problems }\end{array}$ & Low risk & $\begin{array}{l}\text { Moderate } \\
\text { risk }\end{array}$ & $\begin{array}{l}\text { Problem } \\
\text { gambling }\end{array}$ & $P$ value \\
\hline Separations from spouse(s) & 0.33 & 0.53 & 0.47 & 0.95 & 0.000 \\
\hline $\begin{array}{l}\text { Serious personal or family member } \\
\text { injuries/illnesses }\end{array}$ & 2.44 & 2.71 & 2.53 & 2.37 & 0.221 \\
\hline $\begin{array}{l}\text { Deaths of spouse, child, close family } \\
\text { member or close friend }\end{array}$ & 2.33 & 2.68 & 2.69 & 2.46 & 0.005 \\
\hline $\begin{array}{l}\text { Victim of physical violence or property } \\
\text { crimes }\end{array}$ & 0.55 & 0.71 & 0.7 & 1.07 & 0.000 \\
\hline Self or close family member detained in jail & 0.14 & 0.27 & 0.22 & 0.53 & 0.000 \\
\hline Fired or made redundant & 0.31 & 0.42 & 0.43 & 0.57 & 0.000 \\
\hline Major worsening in finances & 0.30 & 0.33 & 0.35 & 0.65 & 0.000 \\
\hline Changed residence & 1.64 & 1.71 & 1.76 & 1.75 & 0.581 \\
\hline
\end{tabular}

Notes:

1. Gambling risk was measured in 2015.

2. $P$ values are associated with a 1-way analysis of variance.

3. The data reported in the table include people who responded to wave 15 but did not respond to one or more of the earlier waves (ie it is an unbalanced panel).

Source: Household Income and Labour Dynamics in Australia (release 15)

is 'changed residence', which may be positive or negative, although the evidence is that it is likely to be stressful. Differences in the cumulative experience of negative major life events over the period 2002-15, according to level of gambling risk, are presented in Table 5.

As an example of how to interpret this measure, Table 5 shows that respondents who report no problems from gambling had, on average, 0.33 separations from a spouse, those who were low risk had 0.53 separations, those with moderate risk had 0.47 separations, and those with problem gambling had 0.95 separations. That is, those who report problem gambling are also more likely to have experienced separation than those who are not problem gamblers. Only the response categories that are likely to be negative are reported in Tables 5 and A.2, so, for example, marriage is not reported.
Problem gamblers experienced more negative major life events than those who are low- or moderate-risk gamblers and those with no problems related to gambling. In some cases the differences are very large. Notable examples are self or close family being detained in jail, being a victim of physical or property crime, and experiencing a major worsening of finances. The differences between low- and moderaterisk gamblers in experiencing negative major life events varies according to the event being considered; the differences are generally quite small. ${ }^{9}$ 


\section{Conclusion}

This paper makes use of a new longitudinal data source that has, for the first time, included questions on gambling behaviour in Australia - the HILDA survey. Although the HILDA survey currently provides longitudinal data for the period 2001 to 2015, it only provides data on gambling in the 2015 wave of the survey. Throughout this paper, we use the HILDA survey to ask the question: looking back, are there differences in a range of economic, social and health outcomes between high-, low- and moderate-risk gamblers and those without any gambling-related problems (either because they gamble without problems or do not gamble at all)?

The analysis clearly shows that problem gamblers experience significantly worse outcomes than those without gambling problems, and poor outcomes are found going back a number of years. In a number of cases, outcomes are becoming progressively poorer, which may suggest either increasingly risky gambling behaviour or the cumulative effects of a sustained period of problem gambling. Low- and moderate-risk gamblers have better economic, social and health outcomes than problem gamblers, but, in most cases, worse outcomes than those without gambling-related problems. Again, these differences go back a number of years.

From 2002 to 2015, problem gamblers, as measured in 2015, are much more likely to have experienced a range of significant negative life experiences, including divorce, being a victim of crime, and the respondent or a close family member being jailed. Although the direction of causation cannot be determined using the existing HILDA data, the finding of high levels of financial stress and high-risk problem gambling going back a number of years demonstrates a strong association between problem gambling and financial hardship. While this finding is hardly surprising, the long duration of the financial hardship is an important finding. The lower rates of life satisfaction and higher rates of high or very high psychological distress of problem gamblers going back a decade or more are, however, suggestive that these are risk factors for becoming a problem gambler, with the direction of causation likely to go in both directions. As further waves of HILDA are collected, the issue of the direction of causation between the gambling behaviour and aspects of wellbeing will be analysed.

Multivariate analysis of the cross-sectional contemporaneous relationship between gambling risk behaviour and outcomes shows that the relationship between increasing gambling risk and worsening outcomes is not solely explained by differences in a range of demographic and human capital characteristics between gambling risk groups.

High-risk problem gamblers experience financial hardship at 4 times the rate of people who do not report problems, and this experience of financial hardship is sustained over many years. Overdue household, personal and credit card bills are also highly characteristic of people who experience gambling harm compared with those who do not, and again appears to be a reported issue for a sustained time. High-risk problem gamblers are 4-6 times more likely to take above-average financial risks than any other at-risk group or those experiencing no problems. Further to this, people who are high-risk problem gamblers experience significantly lower levels of life satisfaction than those who do not experience problems. They also experience high and very high levels of psychological distress, at 3 times the rate of people experiencing no problems. This elevated level of psychological distress is also something that is sustained over a long time. Higher levels of alcohol consumption and smoking are also characteristic of problem gambling risk.

As future waves of HILDA with gambling questions become available, it will be possible to examine ongoing outcomes according to gambling risk as well as the effect of changes in gambling risk on outcomes. This will provide an important contribution to the understanding of gambling behaviours, associated outcomes and policy responses. 


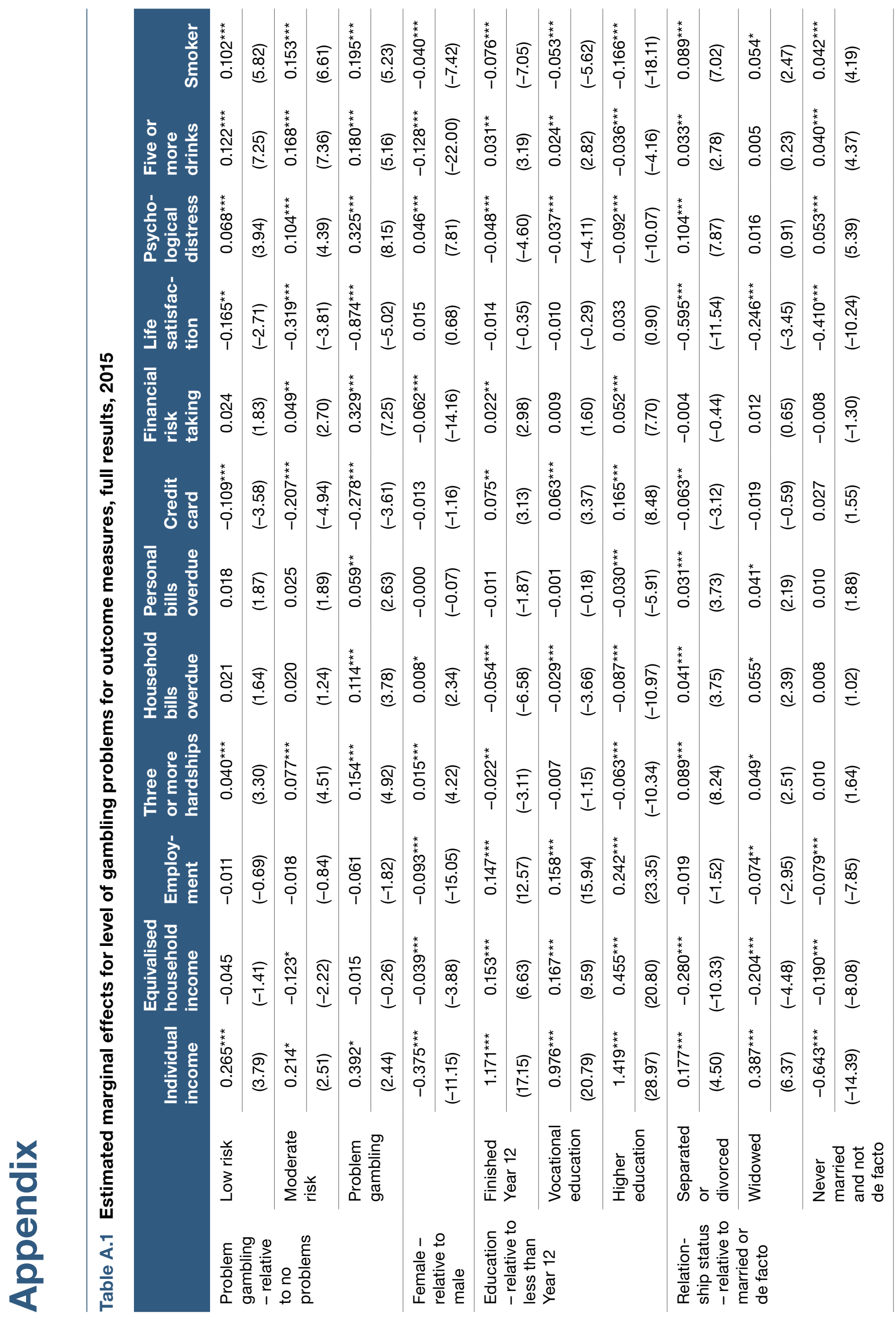




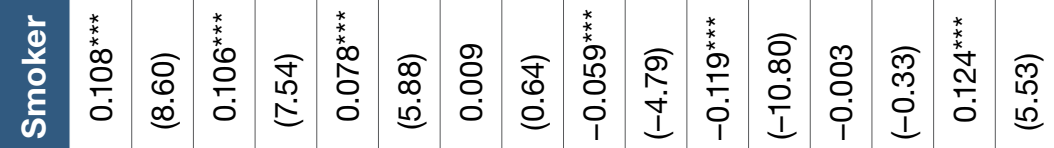

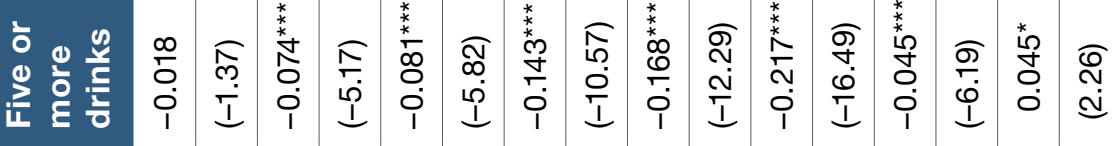

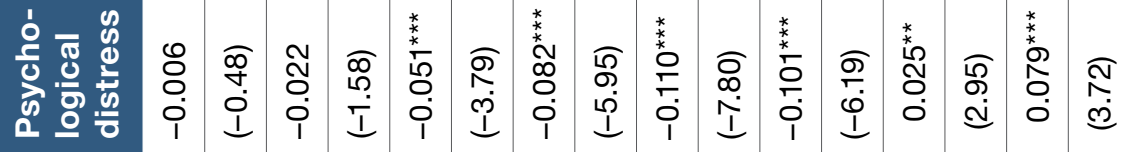

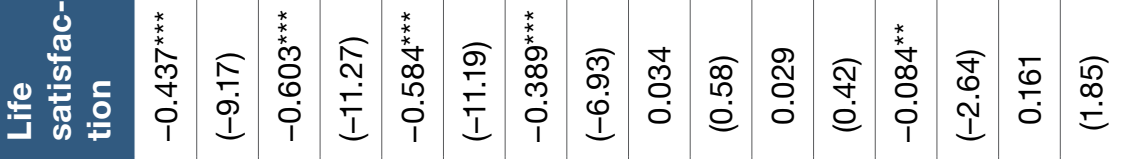

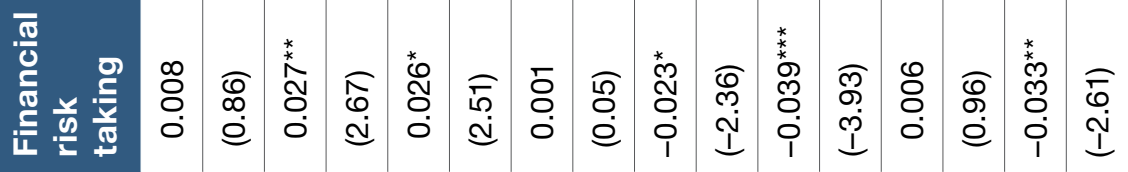

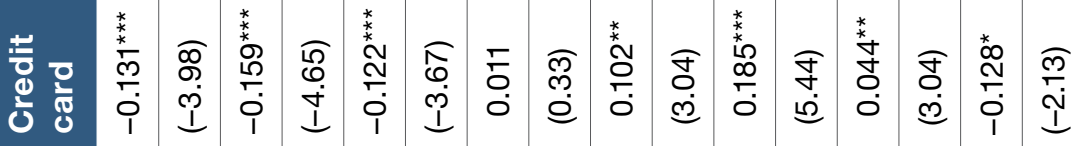

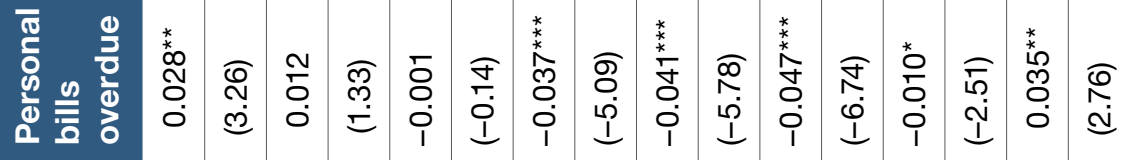

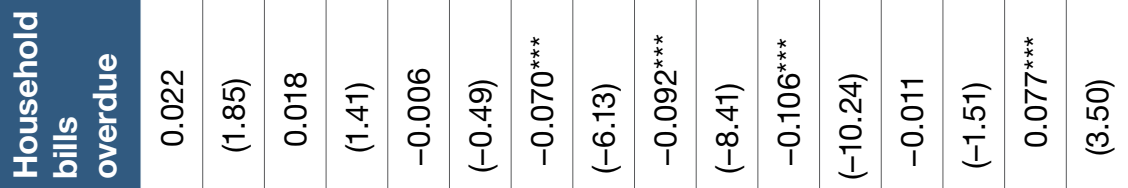

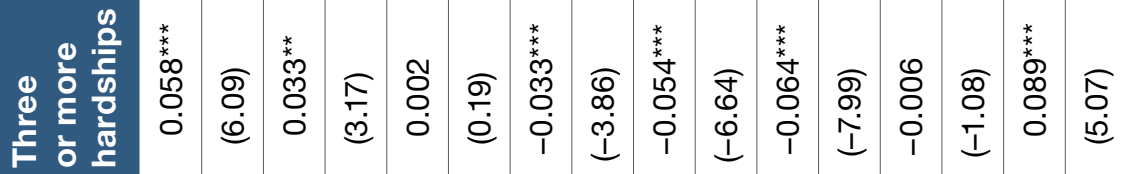

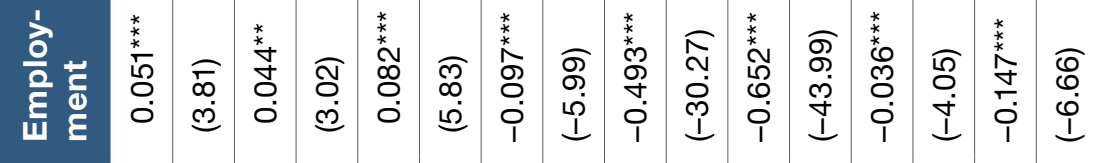

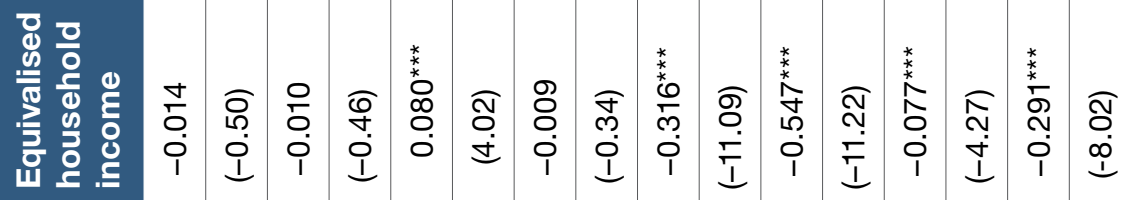

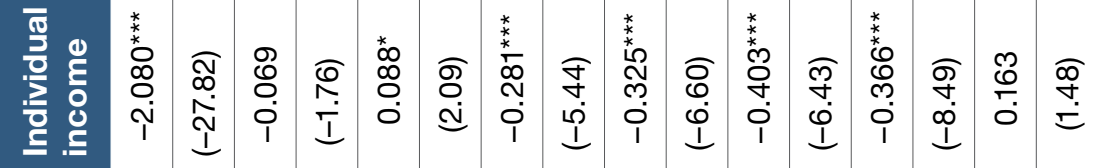

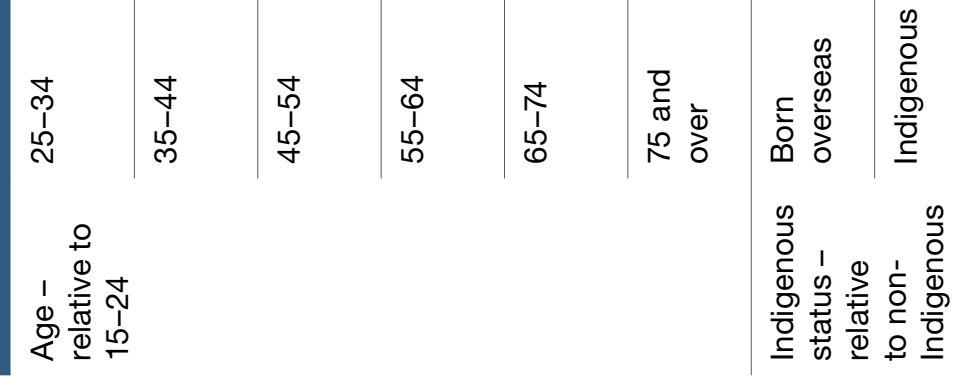




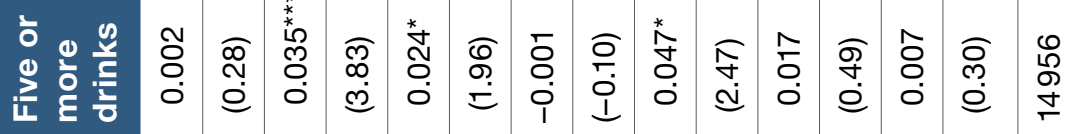

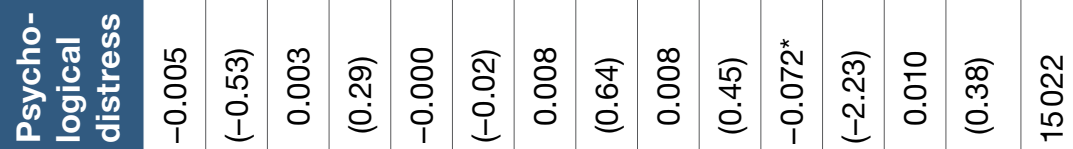

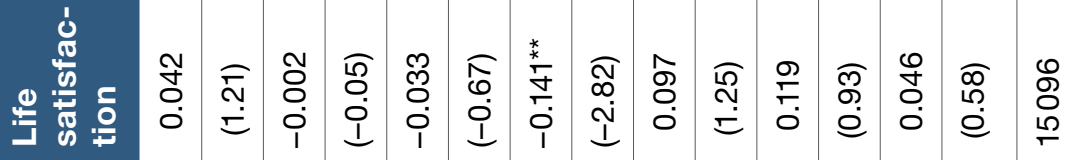
带

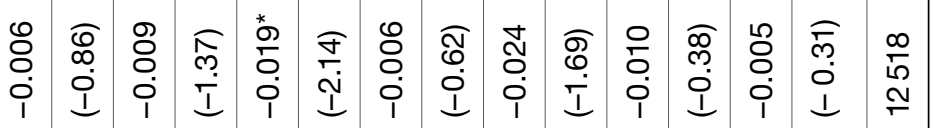

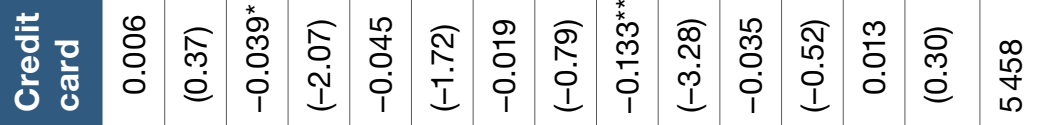

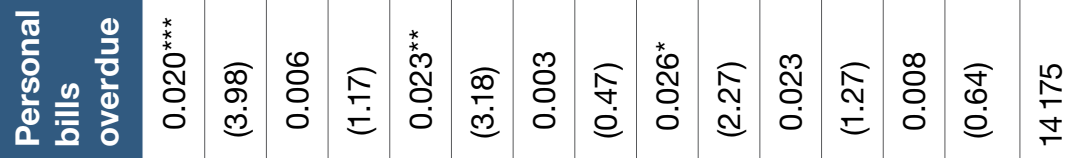

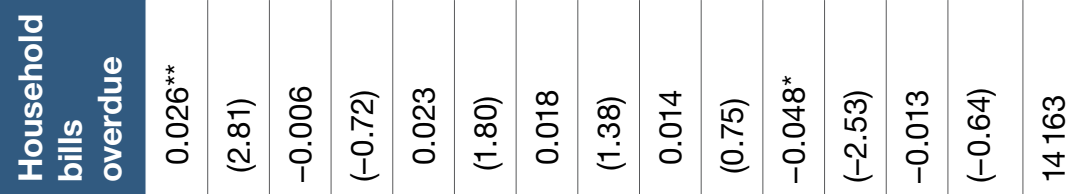

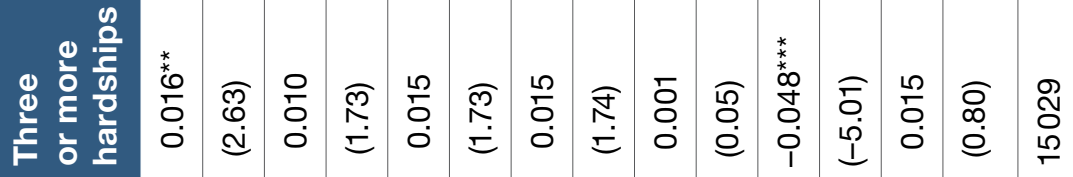

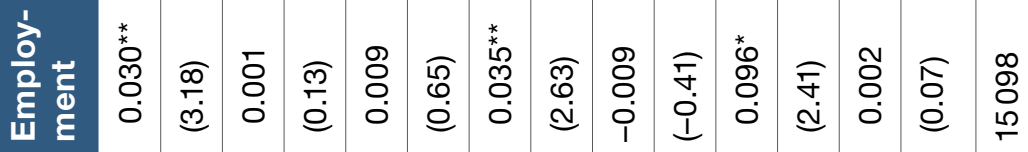
융 응 
Table A.2 Number of major life events experienced between wave 11 and 15 by level of gambling problems (balanced panel)

\begin{tabular}{lcccc} 
Event & $\begin{array}{c}\text { No } \\
\text { problems }\end{array}$ & $\begin{array}{c}\text { Low } \\
\text { risk }\end{array}$ & $\begin{array}{c}\text { Medium } \\
\text { risk }\end{array}$ & $\begin{array}{c}\text { Problem } \\
\text { gambling }\end{array}$ \\
\hline Separations from spouse(s) & 0.14 & 0.27 & 0.2 & 0.42 \\
\hline Serious personal or family member injuries/illnesses & 1.17 & 1.29 & 1.3 & 1.26 \\
\hline $\begin{array}{l}\text { Deaths of spouse, child, close family member or } \\
\text { close friend }\end{array}$ & 1.16 & 1.29 & 1.33 & 1.41 \\
\hline Victim of physical violence or property crimes & 0.21 & 0.29 & 0.22 & 0.5 \\
\hline Self or close family member detained in jail & 0.06 & 0.13 & 0.09 & 0.23 \\
\hline Fired or made redundant & 0.15 & 0.22 & 0.12 & 0.25 \\
\hline Major worsening in finances & 0.13 & 0.18 & 0.17 & 0.32 \\
\hline Changed residence & 0.68 & 0.74 & 0.64 & 0.77
\end{tabular}

Notes:

1. Gambling risk was measured in 2015.

2. The data reported in the table are restricted to people who responded to all waves from wave 11 to wave 15 (ie it is a balanced panel). 


\section{Notes}

1. When the analysis for the paper was being done, the 2015 wave of HILDA data was the most recent available. In future work, we intend to use post-2015 HILDA data to extend the analysis to trajectories after the time at which gambling risk was first measured in HILDA.

2. Although HILDA includes reported expenditure on a range of gambling activities, respondents are asked: 'In a typical month, roughly how much do you spend on the following activities?' rather than whether they have made expenditure in the previous 12 months. Insofar as this is a departure from the design of the PGSI, the authors do not deem it appropriate to use these expenditure variables to partition our category of 'no problems' into the PGSI categories 'nongambling' and 'nonproblem gambling'.

3. Not all of those who returned the SCQ provided valid responses: 237 did not answer the questions on gambling and 1 provided multiple responses.

4. As indicated in Table 2, some outcome measures are only measured in wave 14 .

5. Armstrong and Carroll's (2017) analysis of HILDA data found that gambling incidence was higher among full-time employees than among unemployed individuals and part-time employees. However, the 2012 New South Wales gambling and problem gambling prevalence study found that unemployed respondents were 2.5 times more likely than those in full-time employment to be in the problem/moderate-risk category (Ogilvy Illumination 2012). The 2015 Northern Territory gambling prevalence survey found labour force status was significantly associated with problem gambling risk - that is, that unemployed and part-time employed had higher problem-gambling prevalence (Stevens et al. 2017).

6. Wooden and Wilkins (2017) analysed the 11-point scale used in HILDA to measure subjective wellbeing and life satisfaction. The results established that problem gamblers, on average, have lower life satisfaction scores and the highest frequency of scores below 5 compared with nongamblers, moderate-risk or low-risk gamblers (Melbourne Institute 2017).
7. The longitudinal Victorian Gambling Study found that the percentage of the sample with severe psychological distress was steady across all four data collection waves (zero-risk participants ranged from $1.4 \%$ to $1.6 \%$, whereas problem gamblers experienced severe psychological distress across all four waves, increasing from $26.0 \%$ to $41.0 \%$; however, these changes were not statistically significant).

8. These data are broadly consistent with the findings of other Australian research (e.g. Davidson et al. 2015).

9. Table 5 includes individuals with missing waves of HILDA because of temporary or permanent sample attrition, or because they entered the survey by reaching the age of 15 or joining the household of a HILDA sample member. To check for robustness, the analysis was repeated for the period 2011 to 2015 for respondents who participated in each wave of HILDA from 2011 to 2015. The conclusions drawn from the longer time period analysis using the unbalanced panel are robust. See Table A.2 in the appendix. 


\section{References}

ACIL Allen Consulting, Social Research Centre \& Problem Gambling Research and Treatment Centre (2015). Third Social and Economic Impact Study of Gambling in Tasmania, vol 3, Assessment of gambling harm minimisation measures, ACIL Allen Consulting, Melbourne.

Armstrong A \& Carroll M (2017). Gambling activity in Australia, Australian Gambling Research Centre, Australian Institute of Family Studies, Melbourne.

Billi R, Stone CA, Marden P \& Yeung K (2014). The Victorian Gambling Study: a longitudinal study of gambling and health in Victoria, 2008-2012, Victorian Responsible Gambling Foundation, Victoria.

Billi R, Stone C, Abbott M \& Yeung K (2015). The Victorian Gambling Study (VGS) a longitudinal study of gambling and health in Victoria 2008-2012: design and methods. International Journal of Mental Health and Addiction 13(2):274-296.

Blaszczynski A, Russell A, Gainsbury S \& Hing N (2015). Mental health and online, land-based and mixed gamblers. Journal of Gambling Studies 32:261-275.

Davidson T, Rodgers B, Taylor-Rodgers E, Suomi A \& Lucas N (2015). 2014 Survey on Gambling, Health and Wellbeing in the ACT, ACT Gambling and Racing Commission, Canberra.

Delfabbro P, King D \& Griffiths MD (2014). From adolescent to adult gambling: an analysis of longitudinal gambling patterns in South Australia. Journal of Gambling Studies 30(3):547-563.

Ferris J \& Wynne H (2001). The Canadian Problem Gambling Index: final report, Canadian Consortium for Gambling Research.

Hare S (2015). Study of gambling and health in Victoria: findings from the Victorian Prevalence Study 2014, Victorian Responsible Gambling Foundation \& Victorian Department of Justice and Regulation, Melbourne.
Holdsworth L, Nuske E \& Hing N (2015). A grounded theory of the influences of significant life events, psychological co-morbidities and related social factors on gambling involvement. International Journal of Mental Health and Addiction 13(2):257-273.

Kessler RC, Andrews G, Colpe L, Hiripi E, Mroczek $D$, Normand S, Walters E \& Zaslavsky A (2002). Short screening scales to monitor population prevalences and trends in nonspecific psychological distress. Psychological Medicine 32:959-976.

Melbourne Institute (2017). The Household, Income and Labour Dynamics in Australia survey: selected findings from waves 1 to 15 , Melbourne Institute of Applied Economic and Social Research, University of Melbourne, Melbourne.

Ogilvy Illumination (2012). Prevalence of gambling and problem gambling in New South Wales, Liquor and Gaming NSW, Sydney.

Stevens M, Thoss M, Barnes T (2017). 2015 Northern Territory Gambling Prevalence and Wellbeing Survey, Menzies School of Health Research, Charles Darwin University, Darwin.

Summerfield M, Freidin S, Hahn M, Li N, Macalalad N, Mundy L, Watson N, Wilkins R \& Wooden M (2016). HILDA user manual - release 15, Melbourne Institute of Applied Economic and Social Research, University of Melbourne, Melbourne.

Wooden M \& Wilkens R (2017). Gambling. In: The Household, Income and Labour Dynamics in Australia survey: selected findings from waves 1 to 15, Melbourne Institute of Applied Economic and Social Research, University of Melbourne, Melbourne, 78-87. 

CENTRE FOR SOCIAL

RESEARCH \& METHODS

+61261251279

csrm.comms@anu.edu.au

The Australian National University

Canberra ACT 2601 Australia

www.anu.edu.au

CRICOS PROVIDER NO. 00120C 